\title{
Laser Research and Development Studies for Laser Guide Star Systems
}

D. M. Pennington, R. Beach, C. Ebbers, G. V. Erbert, H-H. Nguyen, R. Page, S. Payne, and M. D. Perry

February 23, 2000

U.S. Department of Energy

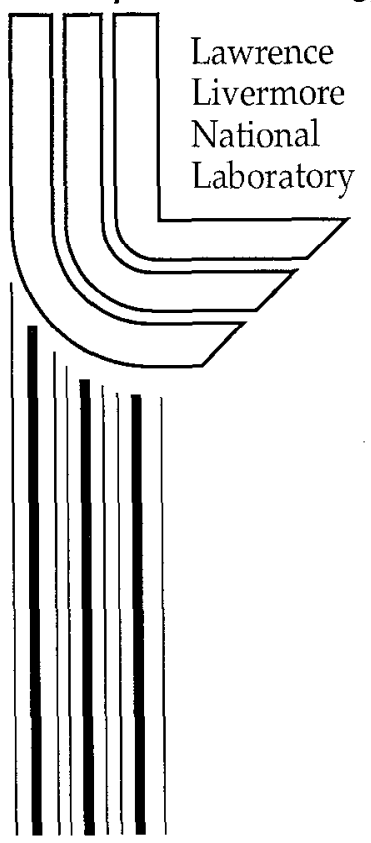




\section{DISCLAIMER}

This document was prepared as an account of work sponsored by an agency of the United States Government. Neither the United States Government nor the University of California nor any of their employees, makes any warranty, express or implied, or assumes any legal liability or responsibility for the accuracy, completeness, or usefulness of any information, apparatus, product, or process disclosed, or represents that its use would not infringe privately owned rights. Reference herein to any specific commercial product, process, or service by trade name, trademark, manufacturer, or otherwise, does not necessarily constitute or imply its endorsement, recommendation, or favoring by the United States Government or the University of California. The views and opinions of authors expressed herein do not necessarily state or reflect those of the United States Government or the University of California, and shall not be used for advertising or product endorsement purposes.

Work performed under the auspices of the U. S. Department of Energy by the University of California Lawrence Livermore National Laboratory under Contract W-7405-Eng-48.

This report has been reproduced

directly from the best available copy.

Available to DOE and DOE contractors from the

Office of Scientific and Technical Information

P.O. Box 62, Oak Ridge, TN 37831

Prices available from (423) 576-8401

http://apollo.osti.gov/bridge/

Available to the public from the

National Technical Information Service

U.S. Department of Commerce

5285 Port Royal Rd., Springfield, VA 22161

hllp://www.ntis.gov/

OR

Lawrence Livermore National Laboratory

Technical Information Department's Digital Library

http://www.llnl.gov/tid/Library.html 
Laser Research and Development Studies for Laser Guide Star Systems A White Paper Submitted to the Gemini Telescope Project

February 23, 2000

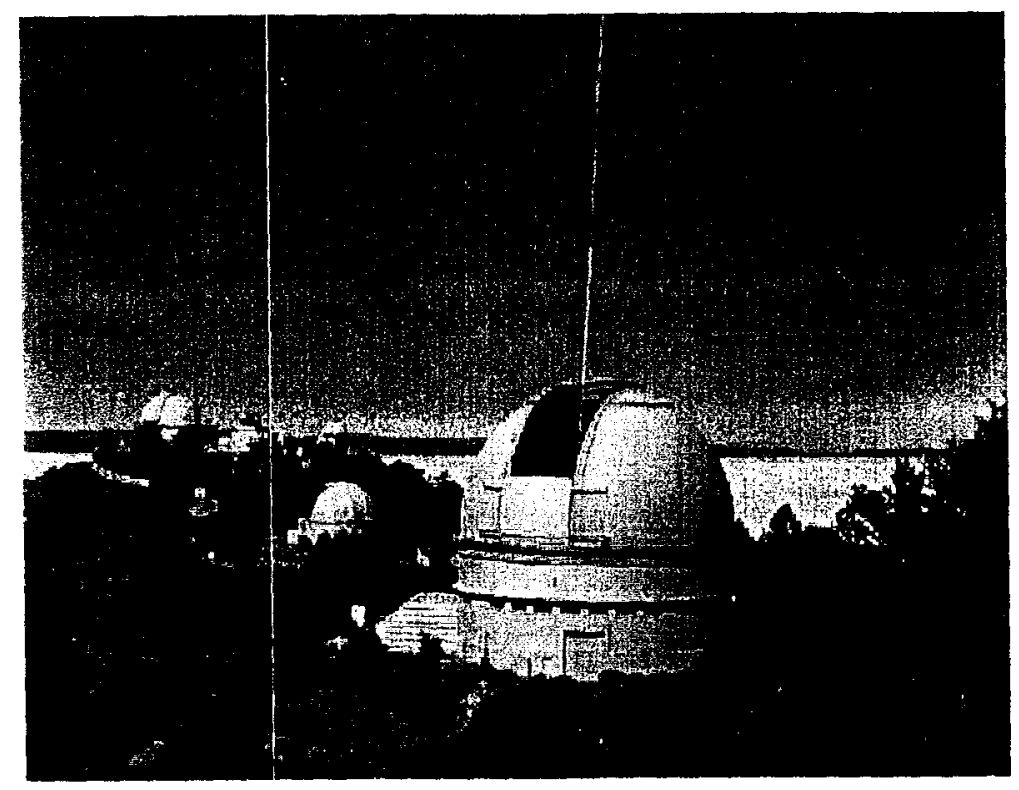

LLNL Laser Guides Star system in operation at Lick Observatory

$\begin{array}{ll}\text { Principal Investigator: } & \text { Dr. Deanna M. Pennington } \\ \text { Co-investigators: } & \text { Dr. Raymond Beach } \\ & \text { Dr. Chris Ebbers } \\ \text { Gaylen V. Erbert } \\ \text { Huy-Hoang Nguyen } \\ \text { Dr. Ralph Page } \\ \text { Dr. Steve Payne } \\ \text { Dr. Michael D. Perry }\end{array}$

Laser Science and Technology Program, L-477

Lawrence Livermore National Laboratory

Livermore, CA 94550 


\section{SECTION I}

\section{Introduction}

The generation of sodium guide stars for adaptive optics requires very precise control of the frequency and bandwidth of the laser to maximize the brightness of the generated guide star. Several laser technologies have been investigated to generate visible light at the sodium D-line for laser guide-star applications. Dye lasers can generate $589 \mathrm{~nm}$ light directly but are limited to a few watts in the CW mode due to thermal issues in the dye jet, as well as the limited pump power available. Pulsed dye lasers have been scaled to the kilowatt level with excellent beam quality and tunable single line output. ${ }^{1,2,3}$ However, these lasers are complex and have high operation and maintenance costs. There are also issues with the toxicity and flammability of the dye mixture. The ruggedness, efficiency and ease of use of a solid state laser system has great potential for improving the reliability and power of the laser guide star over the dye laser systems currently used. Solid-state lasers generating $589 \mathrm{~nm}$ light have been demonstrated by using sum frequency mixing in a non linear material. ${ }^{4-8}$ The systems to date have had a pulsed format, requiring very precise timing of the two independent cavities, as well as high power to generated sufficient intensity in the nonlinear crystal external to the laser cavity. The resulting systems are extremely complicated, high cost and easily damaged, limiting their acceptance in the adaptive optics community. In addition, the high pump powers required for efficient external cavity sumfrequency generation make it challenging to maintain near diffraction limited beam quality.

In this white paper we consider two CW solid state laser approaches to a $589 \mathrm{~nm}$ LGS system. Both are based on the technique of sum-frequency generation, but differ in the cavity architecture. Both technologies are very promising and are worth of further consideration. This preliminary proposal is intended to encompass both designs. A down select shall be performed early in the project execution to focus on the most promising option. The two design options consist of:

1) A dual-frequency resonator with intra-cavity doubling in LBO offers the promise of a simple architecture and may scale more easily to high power. This design has been shown to be highly reliable, efficient and high power when used in frequency-doubled Nd:YAG lasers for programs at LLNL and in commercial products. The challenge in this design is the demonstration of a high power1318 nm oscillator with adequate suppression of the $1064 \mathrm{~nm}$ line.

2) A MOPA based design uses commercial low power oscillators to produce both wavelengths, then amplifies the wavelengths before doubling. This design requires the demonstration of a $1318 \mathrm{~nm}$ amplifier, though the design is scaled from a $\mathrm{kW} \mathrm{CW}$ amplifier already delivered to a customer at a different wavelength. The design must also demonstrate high power scaling of sum-frequency generation in the relatively new nonlinear material, PPLN.

The first step in the process would be to further evaluate the two conceptual options for technical feasibility, cost and constructability. Then a down selection to one design would be conducted. Finally, R\&D on that design would then proceed. Minimal testing should be required for this selection. The majority of the funding received would be allocated to development of the design selected. 


\section{SECTION II}

\section{Option I: Y-branch CW laser system}

Proposed Laser Technology

The laser described in this section is based on sum frequency mixing of the $1064 \mathrm{~nm}$ and 1318 $\mathrm{nm}$ lines in Nd:YAG. Although this technique is not new, the laser described here is unique because generating the two wavelengths and the frequency summing are all done in a single laser resonator. The result is a very simple, efficient all solid-state laser generating $589 \mathrm{~nm}$ light in a single device. A block diagram of the laser system is shown in Figure 1. The laser resonator is split into two branches ( $\mathrm{y}$-branch resonator) using a dichroic mirror. The dichroic mirror is highly reflective for $1318 \mathrm{~nm}$ light and highly transmissive for $1064 \mathrm{~nm}$ light. Each branch contains a diode pumped Nd:YAG rod to generate the respective wavelengths. Etalons in each branch are used for independent line narrowing and tuning. In the common leg of the resonator, where both wavelengths are present, an LBO crystal is used for the frequency summing. The frequency summing process is very efficient in this mode because of the high circulating powers (several hundred watts) of the intra-cavity infrared light. After two passes through the LBO crystal, the $589 \mathrm{~nm}$ light is transmitted through a second dichroic mirror, exiting the laser cavity.

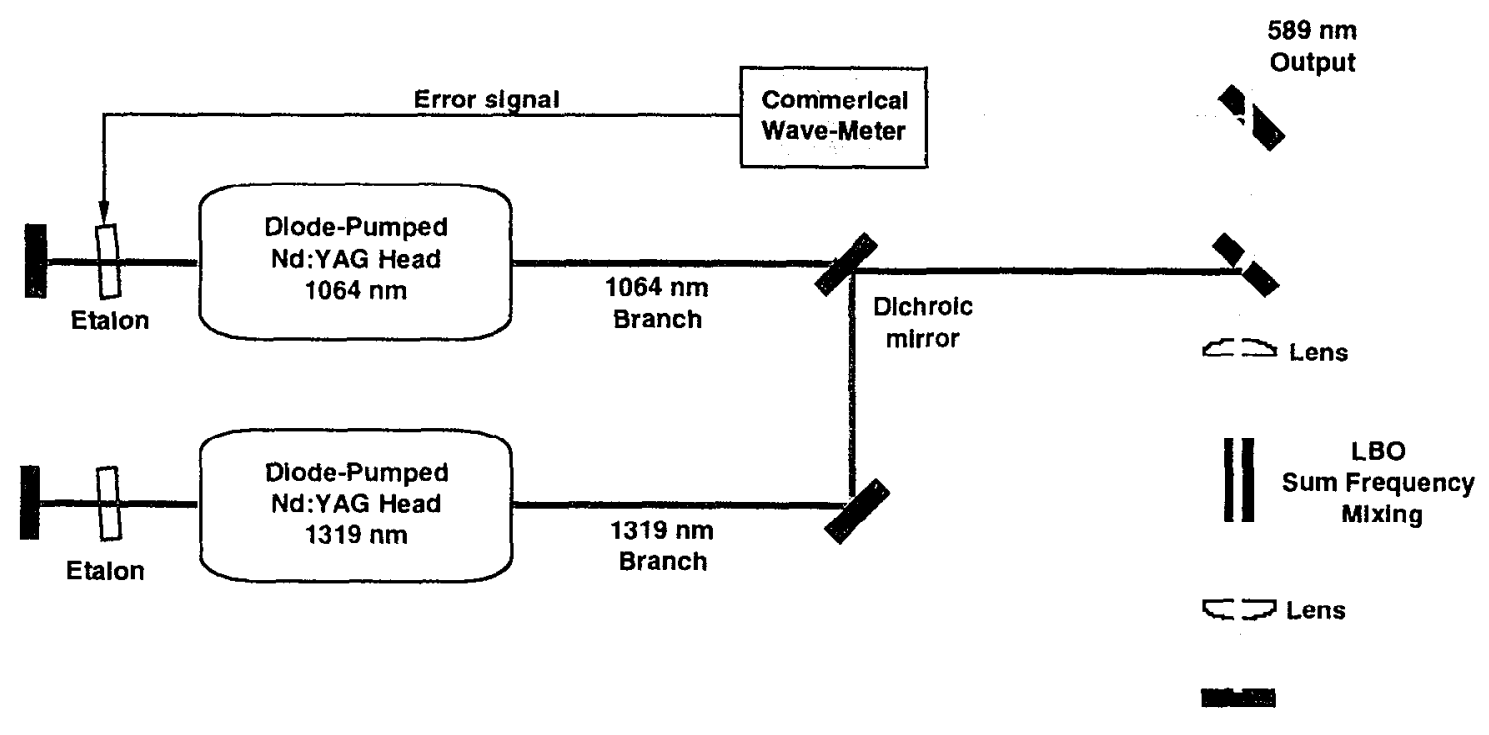

Figure 1. Block diagram of proposed laser design using a y-branch resonator to generate both $1318 \mathrm{~nm}$ and $1064 \mathrm{~nm}$. The two wavelengths are sum frequency mixed in the common leg of the resonator.

The laser design is based on an extension of commercial laser technology which has been developed by several laser companies. Both Coherent and Spectra Physics manufacture 10-watt $\mathrm{CW}$ frequency-doubled lasers in compact turn-key packages, as shown in Fig. 2. ${ }^{9}$ These lasers are housed in a hermetically sealed package and are pumped with diode arrays through fiber optics. The diode arrays are mounted in the power supply where they can be serviced and replaced without affecting the alignment or integrity of the sealed laser unit. Frequency doubled 

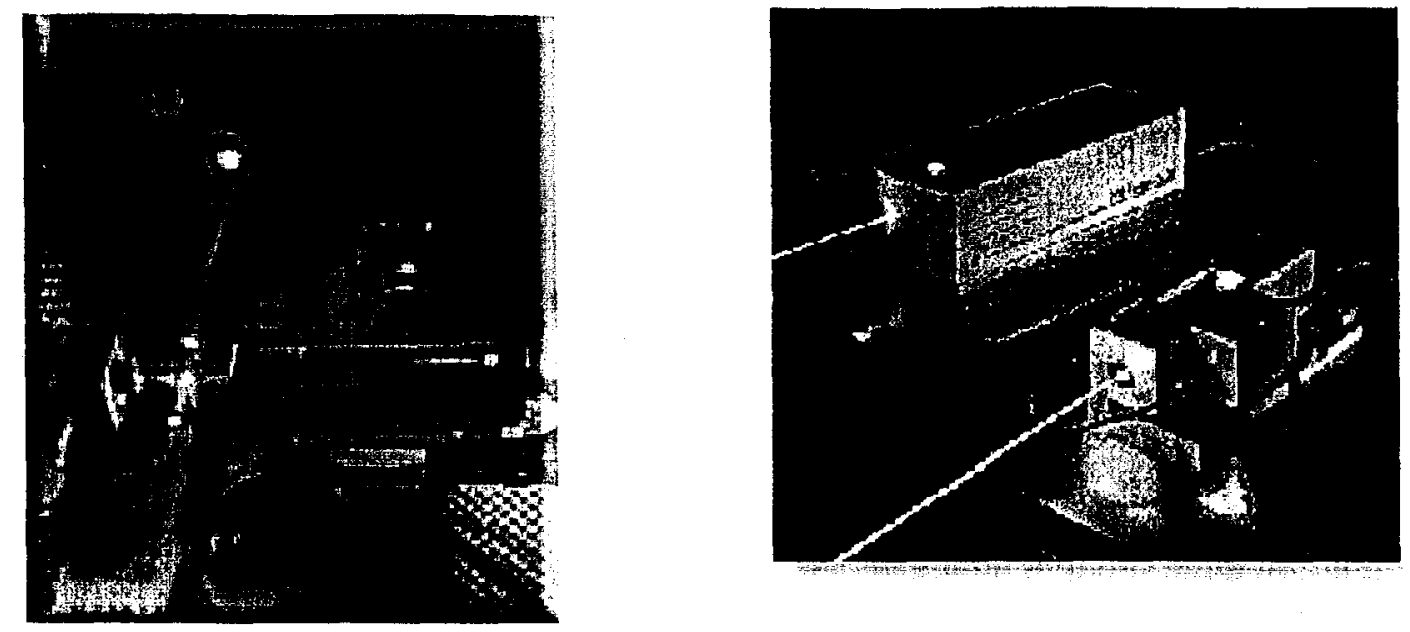

Figure 2: The compact Coherent Verdi and Spectra Physics Millennia lasers. The Millennia is $35 \mathrm{~cm}$ in length.

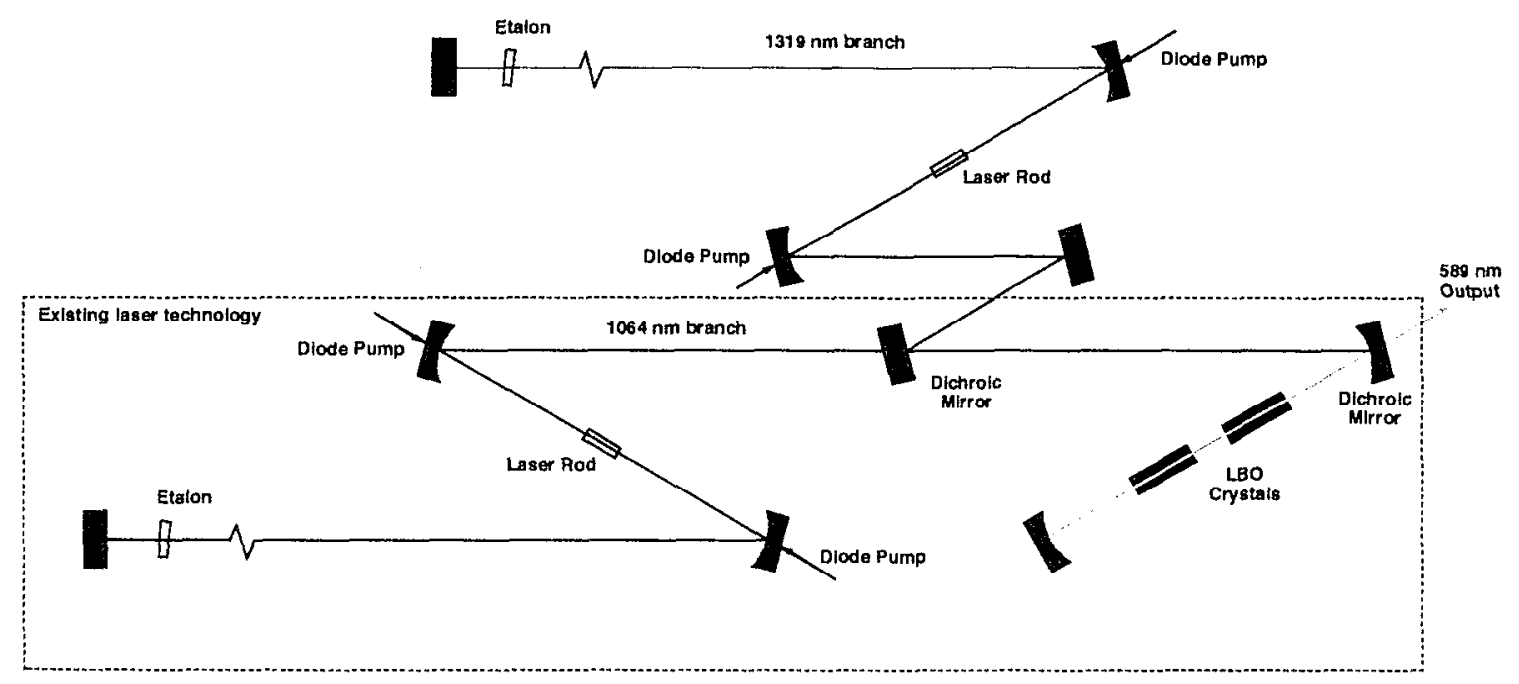

Figure 3. Optical schematic of proposed laser design. The section outline in red laser indicates existing commercial laser technology used to generated $532 \mathrm{~nm}$ radiation.

light at $532 \mathrm{~nm}$ is efficiently generated intra-cavity using LBO. This same laser technology will be used in the proposed laser to generate $589 \mathrm{~nm}$ by splitting the laser resonator into two branches to generate the $1318 \mathrm{~nm}$ and $1064 \mathrm{~nm}$ light. The two infrared wavelengths will be efficiently sum-frequency mixed intracavity in LBO to generate $589 \mathrm{~nm}$ light. Figure 3 shows an optical schematic of the proposed laser system. The portion outlined in red on the optical schematic is what currently exists in the commercial lasers mentioned above. The portion outside the red outline is what would be required to extend this existing laser technology to generate $589 \mathrm{~nm}$ light. All of the components used in the proposed laser design are commercially available. 
Line-narrowing the laser is accomplished with one or two low finesse etalons in each branch of the resonator. In addition, spatial hole burning effects in the laser rods are used to produce a stable spectral output containing two or three adjacent cavity modes. ${ }^{10}$ This is accomplished by placing the rods at the optical center of the laser resonator. In this position, two adjacent cavity modes are 180 degrees out of phase with each other and together access all of the gain preventing other modes from lasing. This technique has been demonstrated in both $\mathrm{CW}$ dye and Ti:sapphire lasers. ${ }^{10,11}$ By centering the transmission peak of the etalons on a cavity mode, the spectral output of the laser is three adjacent cavity modes (each mode $\ll 10 \mathrm{MHz}$ linewidth) with the center mode having twice the intensity of the other two. Each branch of the laser resonator will support three cavity modes separated by the free spectral range of the cavity. These modes are phase locked together (without active control) because they share a common end mirror in the laser resonator. Each of these cavity modes will be frequency mixed in the LBO crystal generating 5 distinct frequencies center around the sodium D-line. 'This mode structure spreads the energy out over the sodium line preventing saturation. Modulating the output of the laser is therefore unnecessary, further simplifying the laser design. The spacing between the 5 modes can be optimized for the highest return signal by adjusting the laser resonator length. With a typical 1-meter long laser cavity, the free spectral range is $150 \mathrm{MHz}$ and would produce a total line-width at $589 \mathrm{~nm}$ of $600 \mathrm{MHz}$ (5 modes spaced $150 \mathrm{MHz}$ apart).

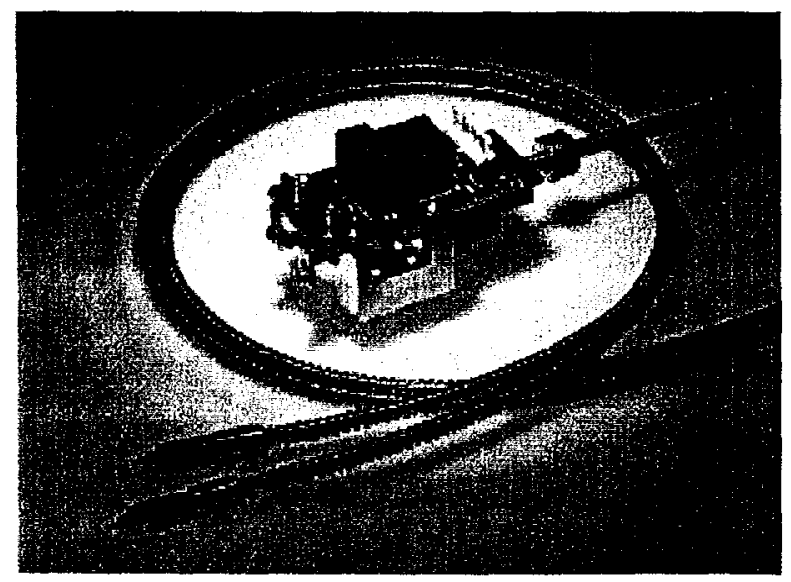

Figure 4: Fiber-coupled diode array.

Locking the laser to the sodium D-line will be achieved using a commercial wavemeter. Commercial CW wavemeters (Burleigh Model WA-1500) have sufficient resolution and can provide an error signal proportional to the difference between a set wavelength and the measured wavelength. The error signal is used to control the etalon in one leg of the laser. Only one leg of the $y$-branch resonator needs to be controlled because tuning the controlled branch can compensate for any drift in the passively locked branch. This feature greatly simplifies the wavelength acquisition and control. Each of the laser rods is end-pumped with commercially available fiber-coupled diode arrays, of the type shown in Fig. 4. The diode arrays are available with output powers up to 40 watts delivered through an 800-micron fiber. Two diode arrays will be used to pump each rod as shown in the Figure 3. End pumping is very efficient because the pump light can be focused to a small diameter in the rod. The pump beam size in the rod is mode-matched to the fundamental mode of the resonator. This ensures single transverse mode operation with excellent beam quality. 


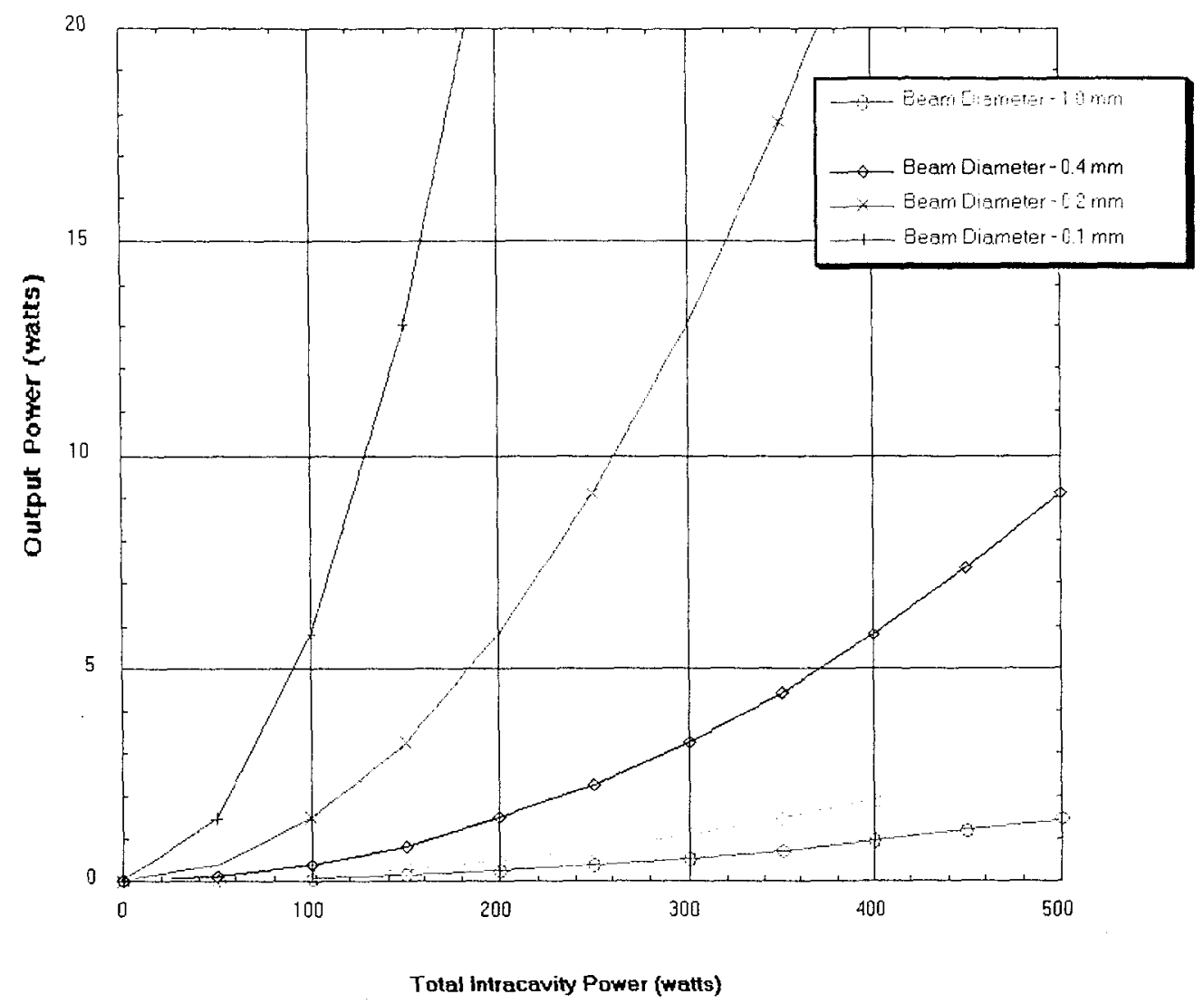

Figure 5: Predicted output power versus intracavity power as a function of beam diameter for intracavity sum-frequency generation using type I LBO in a polarized cavity.

The non-linear material used for frequency summing is LBO. LBO has been used in frequencydoubled laser at output powers in excess of 300 watts at $532 \mathrm{~nm}$ and has proven to be an excellent optical material. The damage threshold is $\sim 600 \mathrm{MW} / \mathrm{cm}^{2}$. Other nonlinear materials, such as PPLN have higher nonlinearity, but are relatively new, and are still in the process of being scaled to high power and large aperture. Figure 5 shows the expected output power as a function of intracavity power for type I sum-frequency generation in a polarized cavity with a single laser head per wavelength. The power output for an unpolarized cavity in Type I LBO is 4 times less than obtained in a polarized cavity. The optical schematic shown in Fig. 3 shows the proposed laser design in its simplest form. In this form, the laser is unpolarized and so type II frequency summing would be used. Two LBO crystals with their optical axes oriented 90 degrees to each other would be used to access all polarizations. There is a potential for instability problems using this technique due to polarization effects. This instability results from orthogonally polarized modes in the cavity coupling through a second sum-frequency process in the nonlinear crystal. ${ }^{12}$ This instability can be resolved by the addition of a quarter-wave plate in the cavity, or by inserting polarizers in each branch of the cavity to polarize the laser. Polarizing the laser adds complexity and cost to the design. In a polarized cavity the LBO would change to type I for optimum conversion efficiency. Compensating for stress-induced birefringence may also be required in the polarized laser to maintain the efficiency and spatial mode quality. Standard techniques using two rods with a quartz rotator in between would be employed, however this would requirc additional development funding. 


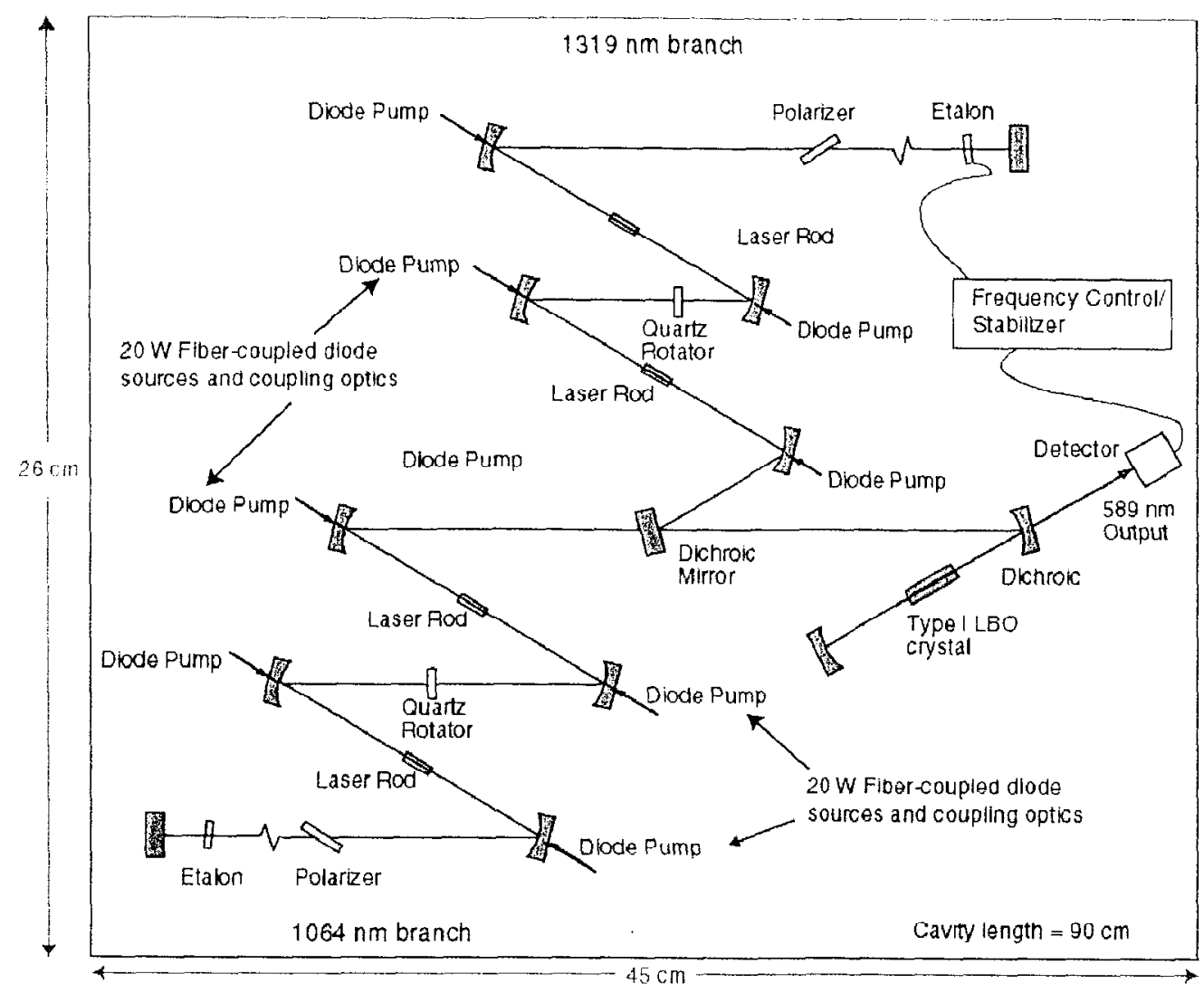

Figure 6: Full power system layout with birefringence compensation.

The upgraded design is shown schematically in Figure 6. We have performed lensing calculations, beam propagation/cavity stability analysis, and modclcd the expected intracavity performance and the expected yellow output power for this preliminary version of the two-rod depolarization-compensating cavity design. The results of these calculations are shown in Fig.7. Each rod is pumped with up to 30 watt from a fiber-coupled diode. The calculations assumed a conservative 5\% depolarization loss (we have achieved better than $3 \%$ with $500 \mathrm{~W}$ of pumping), and $5 \%$ loss optically. To achieve $>5 \mathrm{~W}$ at $589 \mathrm{~nm}$ the required pump power is $>30$ watts for this design. The optical to optical efficiency is not optimal due the conservative losses chosen for these calculations. Note that the single rod unpolarized performance will achievc grcater intracavity power, but the frequency conversion is a factor of four lower. To reach full power (10 $\mathrm{W}$ ), the beam diameter in the LBO needs to be $\sim 100-150$ microns to increase the conversion efficiency. However, with this preliminary design, the smallest spot size achievable was $\sim 220$ microns to maintain reasonable cavity stability. Further modeling is required to optimize the cavity design. A remaining issue of this design is to obtain single frequency operation. Note that this is a preliminary design and will be optimized as part of the proposed research. 


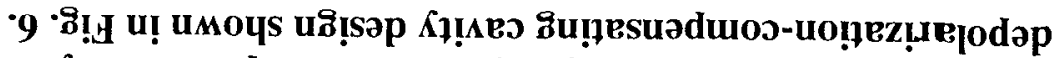

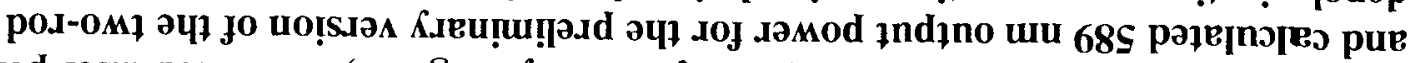

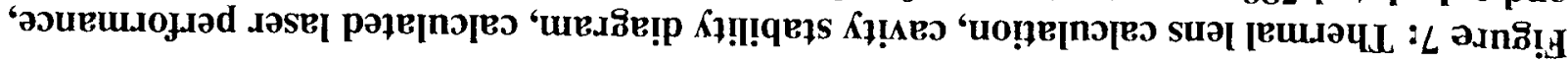

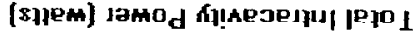
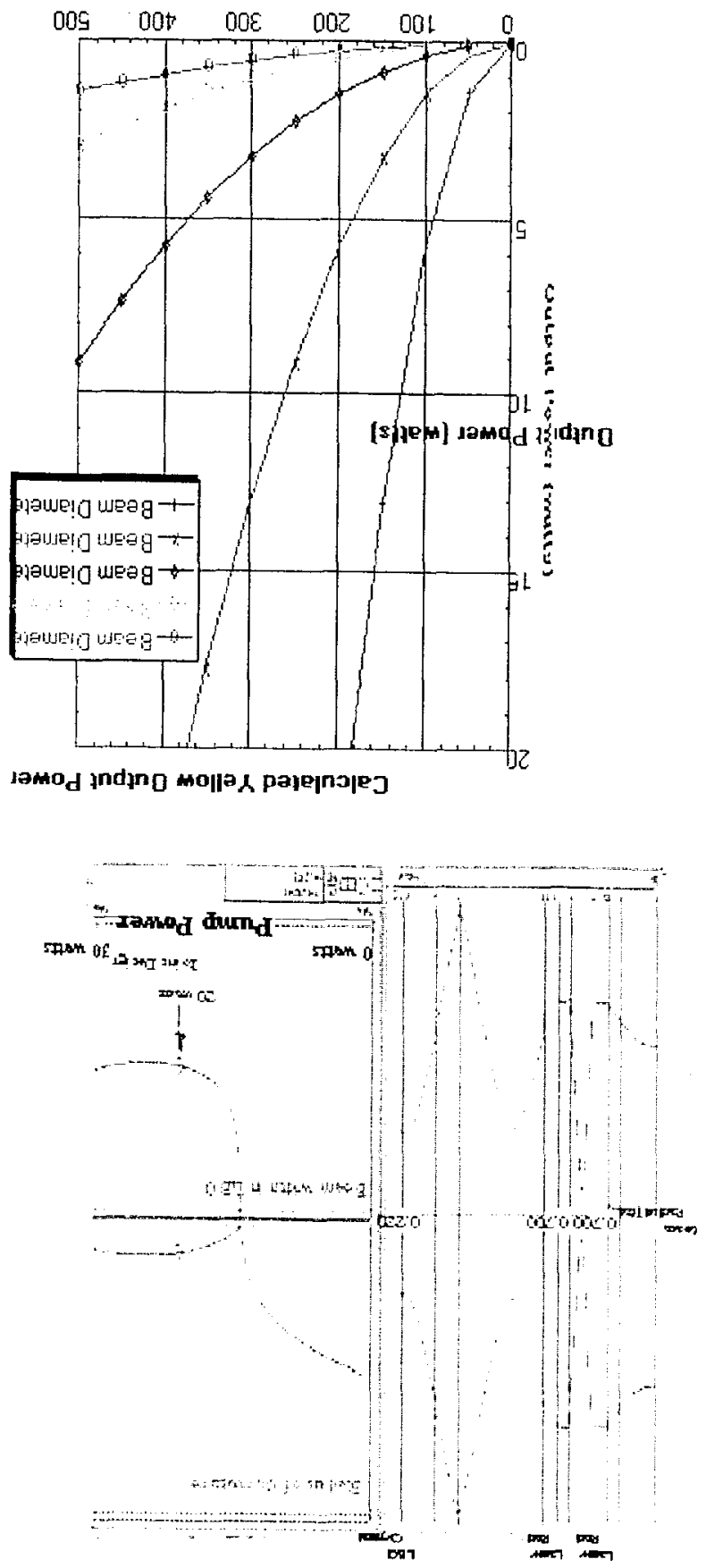

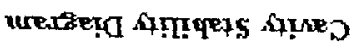

[s]pen] poy jose7 19d jamod dund

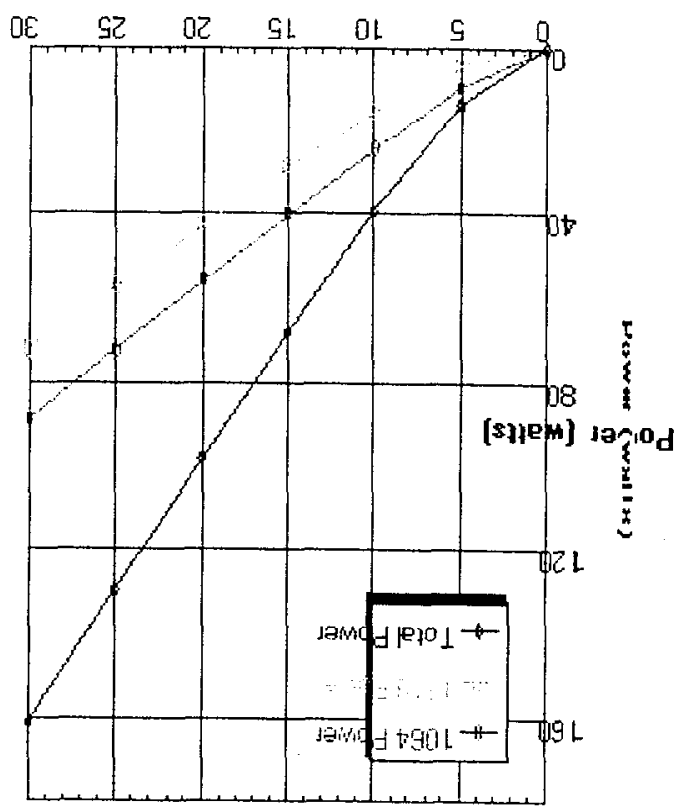

aoupusojed Jaseา pajejnope?

[s]pem] romod durnd

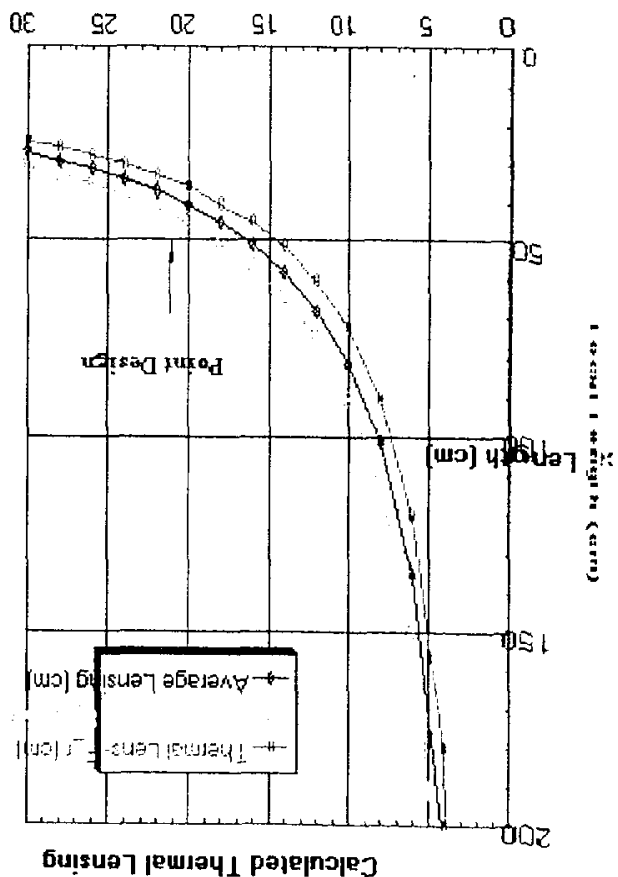


Once the laser system has been demonstrated, commercialization should be straightforward. The advantages of this laser design are outlined below:

1) All solid-state diode-pumped laser design.

2) Single $y$-branch laser resonator generates $589 \mathrm{~nm}$. Multiple lasers with control loops are not required.

3) $\mathrm{CW}$ operation removes the requirement for precise timing between the two laser heads.

4) Uses efficient intra-cavity frequency summing in LBO.

5) Laser design is based on similar existing commercialized laser technology.

6) All major components are commercially available making commercialization straightforward.

7) Design is sufficiently compact to mount on side of the telescope (should fit in location A or B of the original Gemini RFP).

\section{Proposed R\&D Effort}

A cost breakdown of the requested $\$ 285 \mathrm{~K}$ funding is provided below, along with the proposed schedule and work breakdown structure. Upon receiving funding, the design specifications would be finalized, and procurements and fabrication requests would be placed. The first technical task would be the demonstration and characterization of a narrowband $\mathrm{TEM}_{00}$ laser source at $1318 \mathrm{~nm}$. This step has been identified as a critical path item for several of the currently proposed laser systems. The next stage is to evaluate the performance of the $y$-branch resonator at high power. This design has already been demonstrated at low power. ${ }^{13}$ For this proposal, the prototype will be constructed with a single laser head in each arm. In addition, to minimize cost, only two diode arrays would be purchased to pump the laser. Although this would limit the maximum output power to a few watts, all other aspects of the design could be tested. Under this development effort we would initially build the unpolarized laser to demonstrate the basic concept and identify any issues in the design. The use of 2 LBO crystals oriented 90 degrees to each other to access all polarizations would be evaluated. In addition, laser output parameters such as bandwidth, line narrowing, beam quality and wavelength would be documented.

Should polarization effects prove to be an issue, the cavity could be modified to include polarizers in each branch of the cavity, while substituting type I LBO in the frequency summing arm. This would allow the evaluation of the resulting power and any additional design issues. The power loss from polarizing the cavity could be recouped by adding a second laser head to one or both arms, along with a rotator, to increase the cavity gain and mode quality to meet the full system requirement. Further calculations are required to finalize a cavity design that addresses the technical issues discussed above. Construction of this final design with 2 additional heads would require additional development funding at the $\$ 60-80 \mathrm{~K}$ level. Again, this upgrade should meet the $10 \mathrm{~W}$ design criteria, as well as provide sufficient power margin to compensate for periods of low $\mathrm{Na}$ in the atmosphere. Once the prototype has been demonstrated, reliability and stability testing would be conducted. All relevant laser parameters would be evaluated and documented in a final report. 


\section{Full-scale system delivery and commercialization}

It would be our intention to build a prototype laser at LLNL. Specifically, the prototype would only include demonstration of the laser design and laser electronics, controls and diagnostics necessary for the initial demonstration. A turn-key laser control system, electronics, diagnostics, summit compatible laser enclosures and cooling systems would be the subject of a subsequent proposal, pending the successful outcome of the research recommended in this white paper. In order to meet the Gemini requirements as well as those of the general astronomy community, it is critical that commercialization of these lasers begin early in the development phase. We have already received an preliminary commitment to commercialize this technology from one industrial supplier, and will continue negotiations once the design phase of this proposal is complete. We have chosen commercial subsystems for the laser, making them amenable to commercialization. If the proposed design is chosen for deployment, it is our intention to partner with a commercial vendor to deliver the single laser system for Gemini North. We would work closely with the vendor to develop the associated systems, transfer the technology and insure that all design criteria are met. This facilitization process would result in the delivery of a turn-key alpha machine for Gemini North. Subsequent units for Gemini South should be available directly from the vendor, presumably at a reduced cost following the initial engineering investment.

References

See end of proposal

\section{Required funding cost breakdown}

\section{Unpolarized cavity;}

Fiber-coupled diode pump lasers

$\$ 50 \mathrm{~K}$

Diode power supplies and temperature controllers $\quad \$ 20 \mathrm{~K}$

Laser Rods and conversion crystals

$\$ 10 \mathrm{~K}$

Control electronics

$\$ 10 \mathrm{~K}$

TE cooler assembly and controller (LLNL provided)

Optics

Hardware

Fabrication

Labor 
Y-branch Schedule

\begin{tabular}{|c|c|c|c|c|c|c|c|c|c|c|}
\hline & $2 / 00$ & $3 / 00$ & $4 / 00$ & $5 / 00$ & $6 / 00$ & $7 / 00$ & $8 / 00$ & $9 / 00$ & $10 / 00$ & $11 / 00$ \\
\hline Proposals & -- & & & & & & & & & \\
\hline $\begin{array}{l}\text { Funding } \\
\text { received }\end{array}$ & & $-\infty$ & & & & & & & & \\
\hline $\begin{array}{l}\text { Detail } \\
\text { Design }\end{array}$ & & & - - - & - & & & & & & \\
\hline Procurements & & & -- & $-\ldots$ & $\ldots$ & & & & & \\
\hline Fabrication & & & - & - & --- & & & & & \\
\hline Assembly & & & & & & --- & & & & \\
\hline $\begin{array}{l}\text { Test and } \\
\text { evaluation }\end{array}$ & & & & & & & & & - & \\
\hline Final Report & & & & & & & & & & -- \\
\hline
\end{tabular}




\section{SECTION III}

\section{Option II: MOPA Configuration}

\section{Proposed Research}

We proposed to build a CW light source using sum-frequency-mixing of two ultra-coherent, high-power Nd:YAG lasers operating at $1064 \mathrm{~nm}$ and $1319 \mathrm{~nm}$. The two lasers have MOPA (Master Oscillator - Power Amplifier) configurations, and the master oscillators (already in our possession, to be used at no cost) are commercial units from Lightwave Electronics. A periodically-poled crystal (lithium tantalate or lithium niobate), whose efficiency far exceeds those of previously-available nonlinear-optical crystals, will be used for frequency-summing. The bandwidth of the $589 \mathrm{~nm}$ output light will be less than $1 \mathrm{MHz}$ with the option of using phase modulation (in the $1319 \mathrm{~nm}$ beam) to add sidebands to achieve an effective bandwidth $\sim 200$ $\mathrm{MHz}$. Output power is projected to reach 10 Watts once the full MOPA powers of 20 Watt per wavelength are achieved (beyond the scope of this proposal.) No resonant cavities or lock loops are required, aside from infrequent laser wavelength monitoring and automatic tuning with a standard CW wavemeter that will maintain the laser at optimum frequency with $<100 \mathrm{MHz}$. resolution. System warm-up time will be $\sim 15$ minutes. Alignment procedures are expected to be straightforward and robust, and the risk of optical damage to be minimal.

We have already generated $589 \mathrm{~nm}$ orange light with this technique at a lower power level of 90 $\mathrm{mW}$ using just the master-oscillator portions of the Nd:YAG lasers. Power scaling is now the main technical goal. Note that the generation of narrowband sodium resonance radiation using a related approach has been reported by Moosmuiller and Vance ${ }^{14}$, albeit without the key ingredient of sum frequency generation using a periodically-poled crystal.

Two main technical risks are evident:

1) Construction of an efficient, high-power (10 - 20 Watt) $1319 \mathrm{~nm}$ power amplifier, and

2) Sum-frequency mixing at high average power in a periodically poled crystal without degradation.

Commercialization is planned to facilitate the proliferation of similar laser systems at various observatories worldwide. Since the components of the proposed system are available as COTS ("commercial off-the-shelf") technology or can be realized with straightforward fabrication procedures, we are confident that commercial availability of the system will not be an impeded by any issues. High-stability $1064 \mathrm{~nm}$ lasers are used in "reprographics" and other applications, and $1319 \mathrm{~nm}$ lasers serve as transmitters in analog fiber-optic telecommunications. The Lightwave Electronics Corporation (Mountain View, California) produces well-engineered, narrowband, diffraction-limited oscillators at both wavelengths. Moosmüller and Vance ${ }^{14}$, have recently shown how these commercially-produced lasers can be integrated into a light source that is very attractive for pumping sodium atoms, by using bulk lithium niobate $\left(\mathrm{LiNbO}_{3}\right)$ as a frequency-mixer, (see Fig. 8.) Alignment of this source is trivial, since the mixing crystal is used in a simple single-pass geometry; the downside is that the mixing efficiency is low, yielding only $\sim 5 \mathrm{~mW}$ of $589 \mathrm{~nm}$ orange light with laser input powers of $\sim 700 \mathrm{~mW}$ and $350 \mathrm{~mW}$. Yet, this source is easy to operate, based on commercial components, reliable, continuously available, easily set on a desired wavelength, not very expensive, and free of liquid-cooling. As we shall 


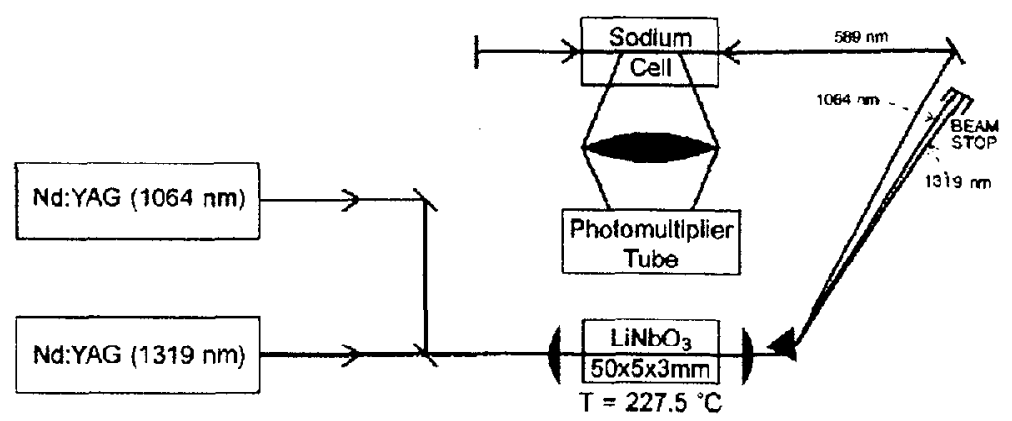

Figure 8: Sum-frequency-generation scheme used by Moosmüller and Vance $^{14}$ to generate $\mathrm{CW}$, narrowband sodium resonance radiation. Increasing the efficiency and power-scaling are the essence of the proposed approach.

see, the substitution of bulk lithium niobate with the periodically-poled version, resolves the efficiency matter.

The Advance Laser and Components Group at LLNL has previously engineered a design in which the $1064 \mathrm{~nm} \mathrm{Nd:YAG} \mathrm{laser} \mathrm{was} \mathrm{replaced} \mathrm{by} \mathrm{a} \mathrm{tunable} \mathrm{Yb:silica} \mathrm{MOPA} \mathrm{laser} \mathrm{system}$ whose wavelength (near $1063 \mathrm{~nm}$ ) was controlled with fiber Bragg gratings. (These sorts of fibers and Bragg gratings have been developed for telecommunications.) Instead of bulk lithium niobate $\left(\mathrm{LiNbO}_{3}\right)$, the mixing crystal was Periodically-Poled Lithium Niobate (PPI .N), whose nonlinear response (and hence conversion efficiency) is many times greater. We achieved CW

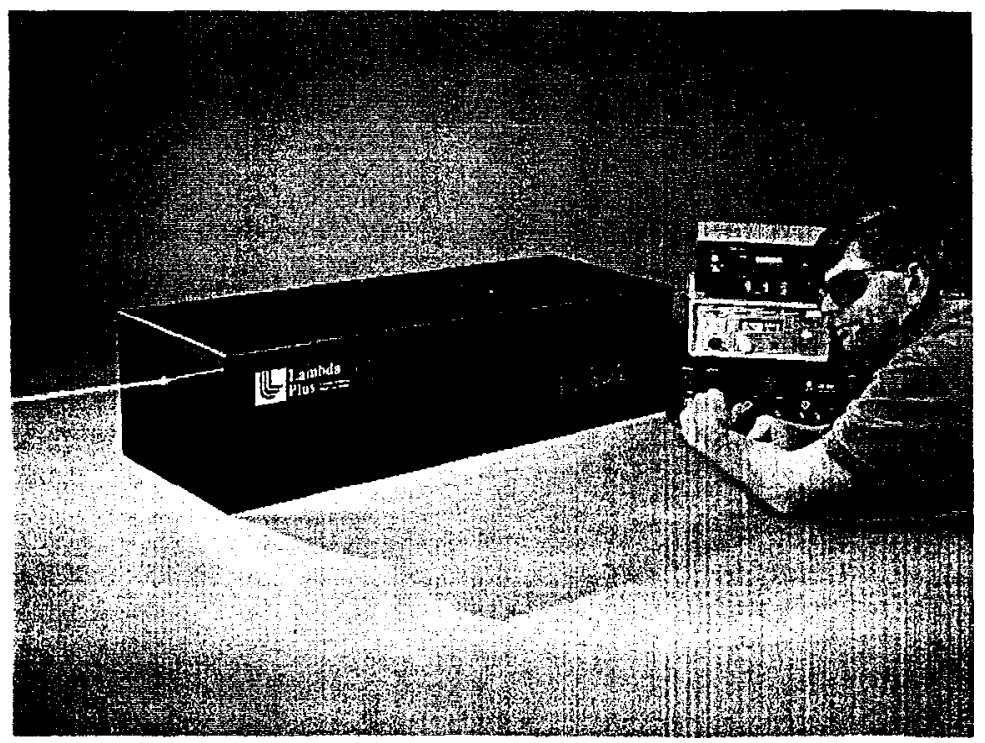

Figure 9: Integrated sum-frequency-mixing visible-light-generation system built in the Advanced Lasers and Components Group at LLNL. To achieve flexible wavelength coverage it employs a tunable Yb:silica fiber laser in place of the fixed $1064 \mathrm{~nm} \mathrm{Nd:YAG}$ laser; the mixing efficiency is enhanced by using PPLN vs. bulk LiNbO3. 
visible powers up to $90 \mathrm{~mW}$, a large advance over the $\sim 5 \mathrm{~mW}$ of the scheme in Fig. 8 . The "beta" version of our very-successful design was an integrated package, as shown in Fig. 9.

Static frequency drift without any wavelength control was quite low - under $2 \mathrm{GHz}$ in 8 hours.

We used an $I_{2}$ cell to check the tuning properties while confirming the excellent spectral purity.

Aside from the modest power level, such a light source meets all the technical requirements for a guide star laser, as evident from the list of characteristics listed in Table I..

Table I. Characteristics of $589 \mathbf{n m}$ visible light source developed at LLNL

\begin{tabular}{|c|c|c|}
\hline $\begin{array}{c}\text { Parameter } \\
1319 \mathrm{~nm} \text { power }\end{array}$ & Value & Remarks \\
\hline $1063 \mathrm{~nm}$ power & $2.4 \mathrm{~mW}$ & $330 \mathrm{~mW}$ at PPLN crystal \\
\hline $589 \mathrm{~nm}$ output & $90 \mathrm{~mW}$ & $2.3 \mathrm{~W}$ at PPLN crystal \\
\hline Beam quality & & $\begin{array}{c}\text { exceeds necessary drive to AVLIS dye } \\
\text { preamplifiers }\end{array}$ \\
\hline Line width & $<47 \mathrm{MHz}$ & near diffraction-limited \\
\hline Passive drift & $2 \mathrm{GHz} / 8 \mathrm{hr}$ & $\begin{array}{c}\text { Mainly fiber oscillator's contribution; no } \\
\text { feedback control in system }\end{array}$ \\
\hline
\end{tabular}

For use as a sodium beacon, there is no need to use $\mathrm{Yb}$ :silica fiber lasers to obtain wide tunability, so we advocate the use of two narrowband Nd:YAG lasers as shown in Fig. 10. To achieve the needed power scale-up from the system in Fig. 8 requires:

1) Use of amplifiers to boost the IR powers to be frequency-mixed.

2) Inclusion of a phase modulator (optional) to broaden the spectrum

3) Use of PPLN (or the variant PPLT) in place of $\mathrm{LiNbO}_{3}$ to increase the conversion efficiency.

A wavemeter is explicitly shown in the diagram to indicate that (1) it completely suffices to control the output (visible) wavelength, and (2) there are no resonant cavities in this system requiring lock loops. These two risk-reduction activities (building a powerful $1319 \mathrm{~nm}$ amplifier, and testing frequency-summing at high power) are required to make this system a reality.

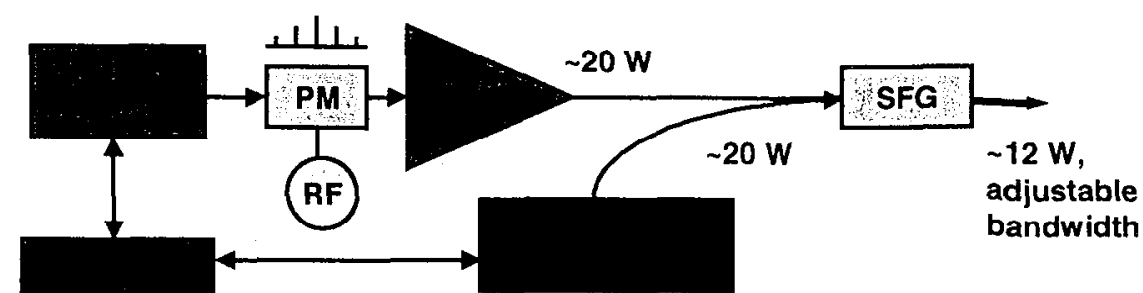

Figure 10: Diagram of proposed next-generation system, whose visible power is scaled to $\sim 12$ Watts. Amplifiers boost the master oscillator signals to $\sim 20$ Watts each, retaining the high spectral purity. All of the components are readily available or can be easily fabricated.

\section{Comparison with Alternative Technologies}

In spite of the increased parts count with respect to power-oscillator schemes, the MOPA approach has the advantage of straightforwardness, predictability, de-coupling of components, and high spectral purity. Each of the two oscillators produces a single mode that will not be affected by amplitication or frequency-mixing. The output light will be single-frequency 
regardless of power level. Deployment of a phase modulator between oscillator and amplifier will produce sidebands at frequency-separations that are multiples of the RF frequency. A low RF frequency $(\sim 10 \mathrm{MHz}$, the $\mathrm{Na}$ natural linewidth) will produce a dense comb of sidebands much more closely-spaced than a typical laser cavity's longitudinal mode spacing. Even a $1 \mathrm{~m}$ laser, which is quite long, has a $150 \mathrm{MHz}$ spacing, such that only a few modes can fit into the $\mathrm{Na}$ Doppler envelope. In principle, the MOPA architecture can be scaled well beyond the $10 \mathrm{~W}$ level with no change in design philosophy.

While amplifier wall-plug efficiencies are typically lower than those of power oscillators, the MOPA approach avoids the problems of tuning and locking a high-power laser (whose spectrum will probably vary with power level, alignment, etc.). On the flip side, one obtains the improvement in reliability and simplicity of operation. The commercial oscillators are easily repaired or replaced. One of the necessary amplifiers (for $1064 \mathrm{~nm}$ ) is already available commercially as well. We note that laser systems designed for other applications (e.g. LIGO, the gravity-wave experiment) requiring ultra-coherent, high-power beams often use the MOPA configuration.

Use of a single-pass frequency-mixing stage (instead of a resonant cavity) also provides increased simplicity because there is no lock loop and no cavity resonances to contend with when the laser is being peaked to the optimum wavelength. Without a high-finesse cavity, slight optical losses become tolerable. (Losses are hard to avoid and come from crystal absorption, surface contamination, imperfection in AR coatings on crystals, and wavefront aberrations caused by surface deformations and refractive-index inhomogeneities.) Moreover, pure CW operation is the simplest mode for any systcm. Pulse-timing issues do not arise, there are no time-dependent gain dynamics or wide power fluctuations in a CW MOPA system. Optical damage is generally eliminated as an issue as well.

Automatic computer control of the light source will be easy to arrange since the various adjustments are decoupled. A computer-interfaced wavemeter will put the two lasers at the exact wavelengths needed, then the computer will temperature-tune the mixing crystal.

\section{Proposed Work and Deliverables}

\section{1319 nm power amplifier}

Construction of a powerful (10-Watt class) $1319 \mathrm{~nm}$ amplifier is perceived as a challenge. We have a credible 2-rod, diode-pumped amplifier design, with many features adapted from previously engineered systems. Our "subscale" design (see below) uses only one Nd:YAG rod but will allow important conclusions to be made about the ultimate power scalability. This "subscale" experimental amplifier will produce between 1.5 and 6 Watts depending on the value of the somewhat uncertain $1319 \mathrm{~nm}$ emission cross section. It will also serve to test our parasitic-suppression approach and the feasibility of working with slender (1 mm) gain elements.

Because one of the primary risk-reduction activities being proposed here is the development of a 10-Watt-class $1319 \mathrm{~nm}$ diode-pumped Nd:YAG amplifier system, we will discuss our design in some detail. Figure 11 shows a schematic drawing of the amplifier design. The main challenge in constructing high-gain $1319 \mathrm{~nm}$ amplifiers is the small ratio $(0.2-0.3)$ of the stimulatedemission cross section for this transition, when compared with the familiar $1064 \mathrm{~nm}$ transition. 
The "open-loop gain" at $1064 \mathrm{~nm}$ is much greater than at $1319 \mathrm{~nm}$, causing potential problems with parasitic oscillation and self-saturation with ASE.

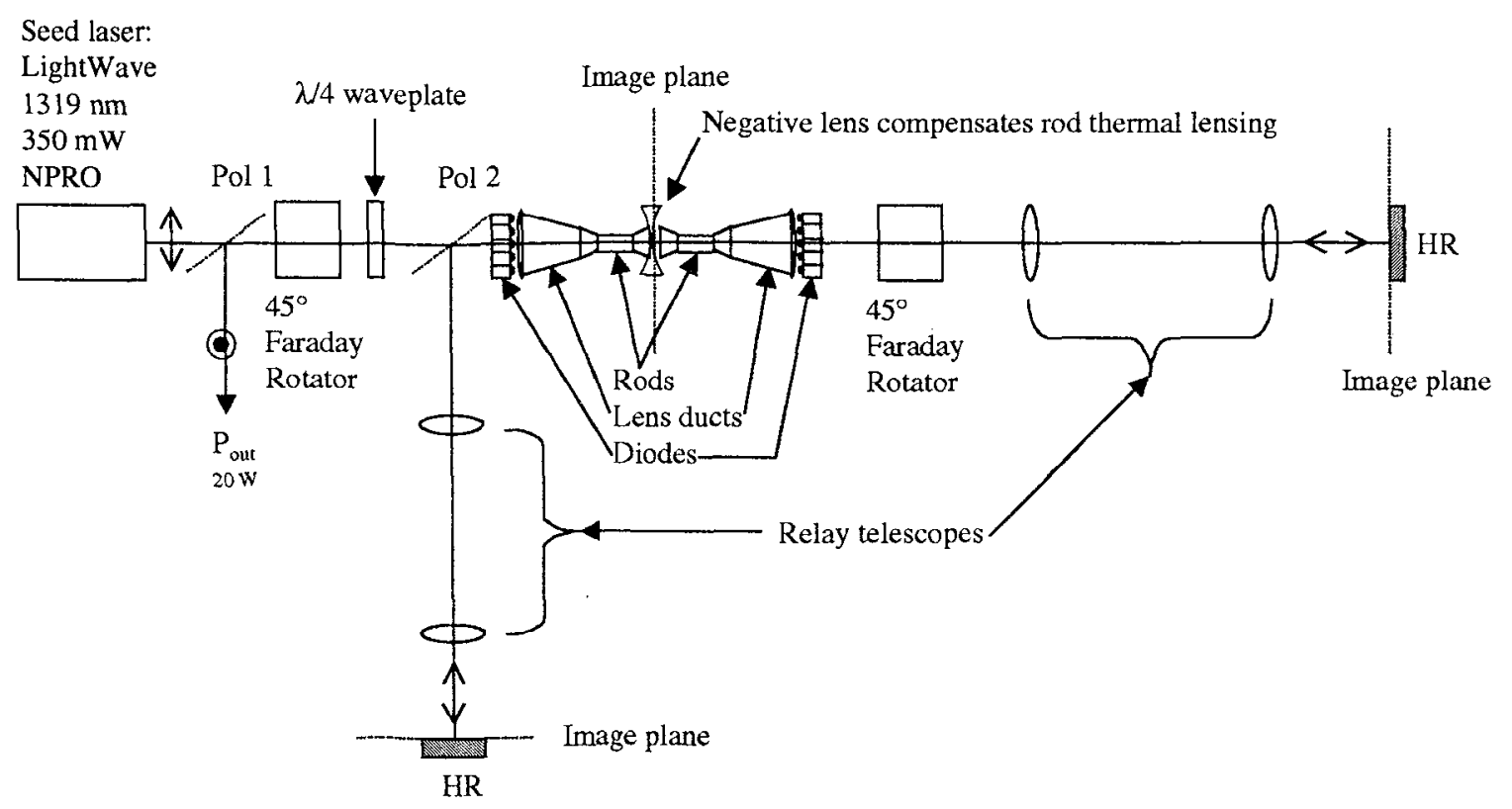

Figure 11: Dual rod, 4-pass, $1319 \mathrm{~nm}$ Nd:YAG amplifier uses an end-pumping technology to efficiently pump the $1 \mathrm{~mm}$ diameter $\mathrm{Nd}$ :YAG laser rods used in the system.

The performance goal of the prototype amplifier is the generation of over $10 \mathrm{~W}$ of CW output power at $1319 \mathrm{~nm}$ using a $350 \mathrm{~mW}$ front-end oscillator. This oscillator (commercially available from Lightwave Electronics) uses a NonPlanar Ring Oscillator (NPRO) geometry ${ }^{15}$ to generate very stable, single line, $\mathrm{CW}$ output radiation. The amplifier section, following the front end oscillator in Fig. 11, contains two Nd:YAG laser rods that are each $1 \mathrm{~mm}$ in diameter and $5 \mathrm{~cm}$ long. Partitioning the gain between two rods reduces the tendency toward parasitic oscillation. The amplifier uses a four-pass configuration in which a standard polarization switching technique is used to inject and extract the laser beam. In this way, efficient use is made of the diode pump power. The negative lens between the rods compensates for the thermal lensing. The two relay telescopes are used to image the plane between the two laser rods back onto that same plane during the four-pass extraction process, further mitigating the thermal lensing. The 45 degree Faraday rotator, to the right of the laser rods, serves to compensate any stress-induced birefringence in the laser rods by rotating the polarization 90 degrees between each successive pass through the two rods, effectively swapping their "fast" and "slow" axes of the radial and tangential polarizations.

The basic technology being utilized in the dual rod amplifier of Fig. 11 was previously developed and demonstrated at a larger scale for a $1 \mathrm{~kW} \mathrm{Yb:YAG} \mathrm{laser} \mathrm{that} \mathrm{we} \mathrm{developed} \mathrm{for}$ Boeing. ${ }^{16}$ This system, shown in Fig. 12 uses a "hollow lens duct" (HLD) pump delivery architecture to funnel diode pump light into the end of a laser rod with an overall pump compression ratio ${ }^{17}$ of 250 . For the $1319 \mathrm{~nm}$ laser system at-hand, a more-modest compression 
ratio of approximately 130 is needed. Therefore, based on our experience with the Boeing system we expect the pump delivery for the $1319 \mathrm{~nm}$ amplifier system to be relatively straightforward.
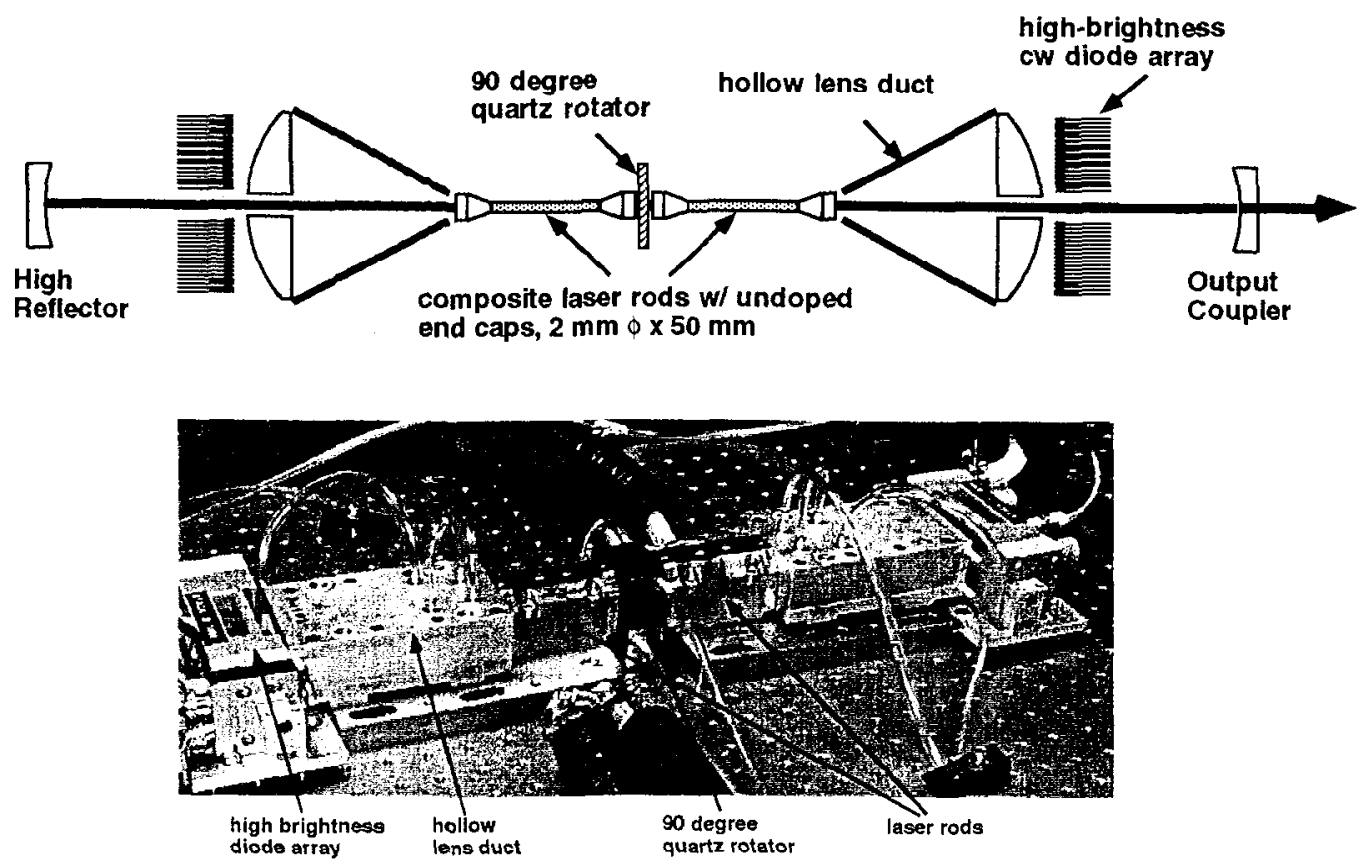

Figure 12: Schematic diagram and photograph of a $1 \mathrm{~kW} \mathrm{CW} \mathrm{Yb:YAG} \mathrm{laser} \mathrm{system} \mathrm{that}$ was developed for Boeing. The basic technology proposed for the $1319 \mathrm{~nm}$ amplifier system of Fig. 11 was developed and demonstrated for this system.

One of the unresolved issues with the design and projected performance of the $1319 \mathrm{~nm}$ amplifier is the uncertainty in the stimulated emission cross section of the $1319 \mathrm{~nm} \mathrm{Nd:YAG}$ ${ }^{4} \mathrm{~F}_{3 / 2}-{ }^{4} \mathrm{I}_{13 / 2}$ transition. This cross-section value has been reported to be between $5.3 \times 10^{-20} \mathrm{~cm}^{2}$ and $11.2 \times 10^{-20} \mathrm{~cm}^{2} .{ }^{18-20}$ Since the projected performance of the laser amplifier varies markedly over this range of emission cross section values, we have conservatively designed our system to generate $>10 \mathrm{~W}$ of CW output even in the worst case (minimum value.) Figure 12 depicts our projected amplifier performance against emission cross section value based on an energetics model we have adapted to investigate and optimize this amplifier system. Table II lists the assumed transmission efficiencies of the various optics used in the cavity shown in Fig. 11 for this modeling exercise. 
Table II. Cavity Component Transmittances

\begin{tabular}{|l|c|}
\hline Description & Value \\
\hline polarizer transmission & 0.99 \\
\hline polarizer reflectivity & 0.99 \\
\hline Faraday rotator transmission & 0.99 \\
\hline $\begin{array}{l}\text { Rod and lens AR coating } \\
\text { transmission at each surface }\end{array}$ & 0.995 \\
\hline
\end{tabular}

With the values in Table II for cavity transmittances, the roundtrip (4-pass) transmission of the amplifier chain depicted in Fig. 11 is 0.74 . To develop the $1319 \mathrm{~nm}$ output powers projected in the Fig. 13 plot, the assumed pump power developed by each diode array at the end of each rod is $125 \mathrm{~W}$. Appropriate diode arrays could either be purchased commercially for example from DILAS or Coherent, or alternatively be fabricated at LLNL using our high average power microchannel-cooler diode packaging technology. ${ }^{21,22}$ Either way, each diode array will consist of six $1 \mathrm{~cm}$ long diode bars configured in a rack and stack configuration, and with each diode bar having its output radiation conditioned by a cylindrical micro-lens that collects and collimates its radiation in the fast axis dimension. This radiation is then delivered into the end of the Nd:YAG laser rods through a hollow lens duct (HLD).

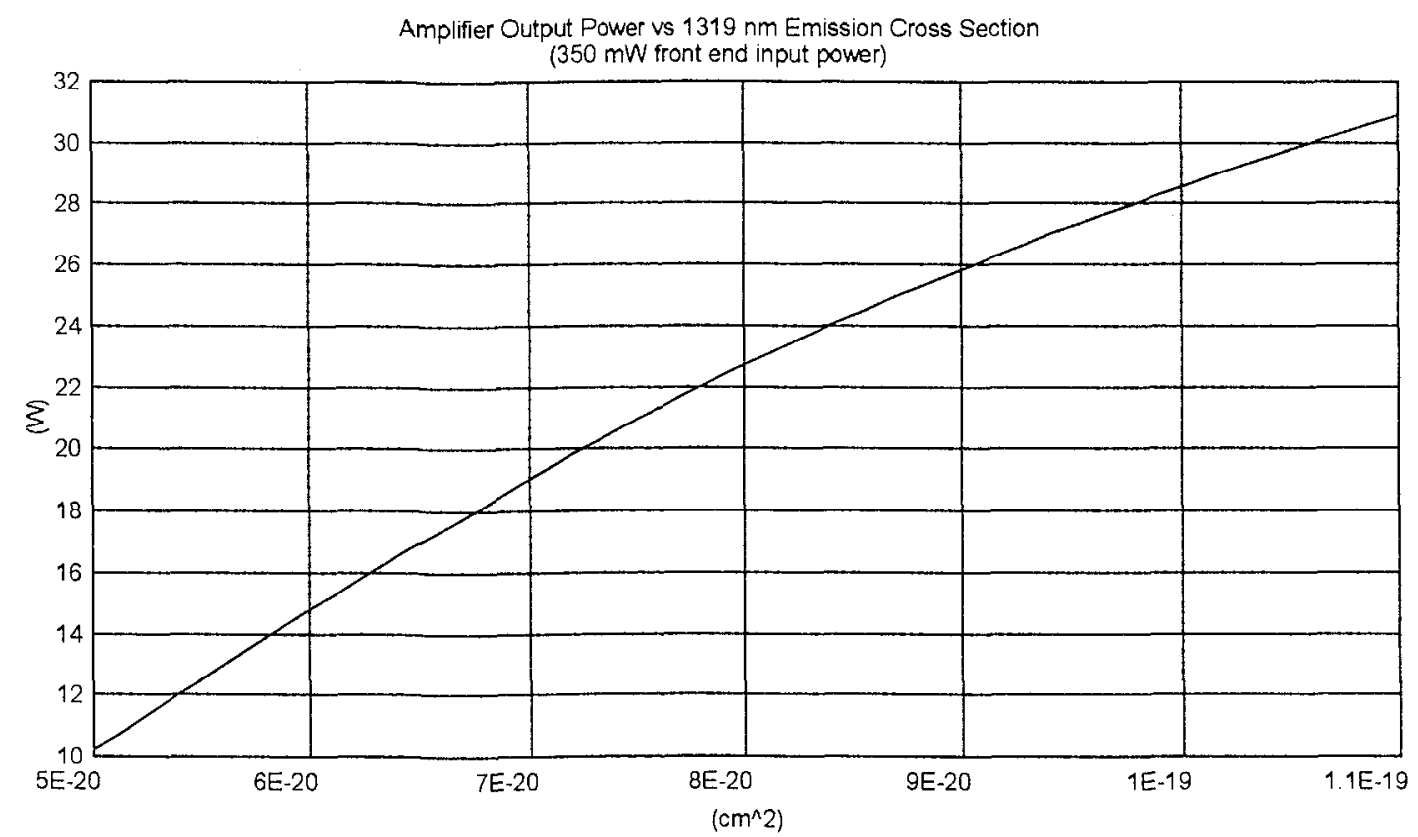

Figure 13: Projected output power from the 4-pass amplifier shown in Fig. 11 as a function of the $1319 \mathrm{~nm}$ stimulated emission cross section value of Nd:YAG. The uncertainty in the value of the $1319 \mathrm{~nm}$ cross section is reflected by the abscissa.

Figure 14 shows a sketch of the HLD that we have developed for the Boeing laser system. A similar design would be used with the $1319 \mathrm{~nm}$ amplifier system depicted in Fig. 11. It will be fabricated from four pieces of aluminum that fit together as shown in Fig. 14. Protected-silver coatings on their inner planar surfaces enhance the reflectivity, improving the pump light delivery. 
The lens at the pump input end of the duct is a commercially procured plano-convex spherical lens that we cut to mate with the lens duct. The milled hole in the lens is situated on the same axis as the hole in the center of the laser diode array, allowing the laser beam to clear the structure unobstructed. The back focal length of the lens is chosen to focus the pump radiation

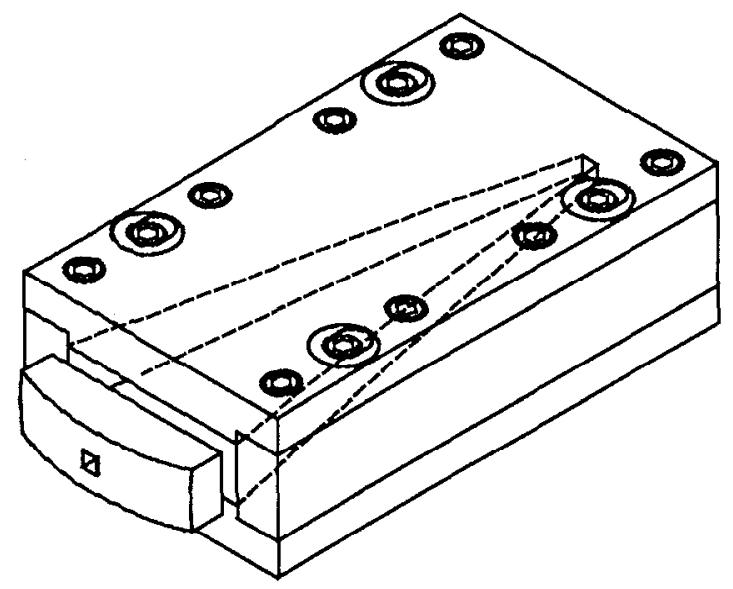

Figure 14: Schematic drawing of hollow lens duct. The spherical lens at the pump input end of the duct has a hole in it to allow the laser beam to exit the assembly unobstructed.

inside the laser rod, so it is slightly longer than the axial length of the HLD. The figure of merit of a hollow lens duct is the efficiency for delivering pump light from the diode array into the laser rod. Figure 15 plots the diode pump power measured both before and after the HLD used with the Boeing Yb:YAG laser system of Fig. 12. Its measured transfer efficiency was $82 \%$ as illustrated in Fig. 15. Based on this data obtained with a high-compression-ratio lens duct, the assumed 80\% pump transfer efficiency in the energetics model projection of the $1319 \mathrm{~nm}$ is deemed to be conservative.

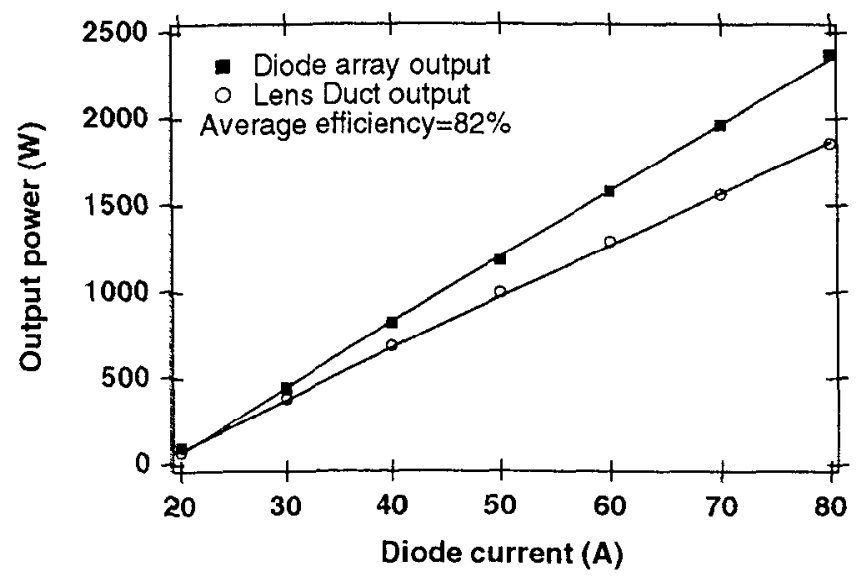

Figure 15: The measured transfer efficiency of the Boeing HLD depicted in Fig. 14. 
Because a $1319 \mathrm{~nm} \mathrm{CW} \mathrm{Nd:YAG} \mathrm{amplifier} \mathrm{has} \mathrm{never} \mathrm{been} \mathrm{demonstrated} \mathrm{with} \mathrm{the} \mathrm{performance}$ we are projecting here, one of the primary tasks we propose in this phase of work is the demonstration of a subscale amplifier system. Basically, we would build the amplifier shown in Fig. 11 but with only a single laser rod and a single diode array, rather than the dual-rod configuration needed to produce over $10 \mathrm{~W}$ of $\mathrm{CW}$ output. Figure 16 depicts our projected performance for the subscale system, again as a function of the (still-uncertain) $1319 \mathrm{~nm}$ emission cross section value.

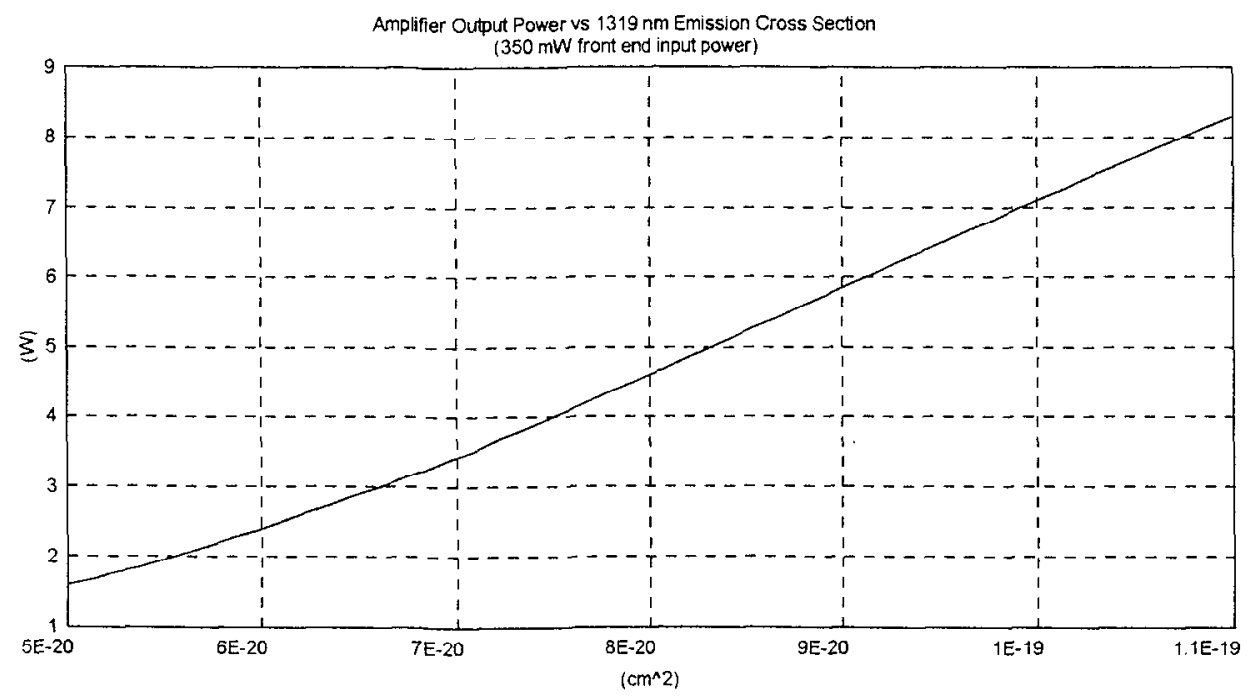

Figure 16: Projected output power from a scaled-down, single-rod, 4-pass amplifier similar to the dual-rod configuration shown in Fig. 11, versus the $1319 \mathrm{~nm}$ stimulated emission cross section value of Nd:YAG.

Conservatively, we are projecting this subscale amplifier system to generate at least $1.5 \mathrm{~W}$ of CW output power at $1319 \mathrm{~nm}$.

\section{High-power frequency conversion: single-pass, $\mathrm{CW}$ frequency mixing}

There are several criteria for selection of a frequency-mixing medium and scheme. As mentioned above, we have already established that single-pass mixing in PPLN (Periodically-Poled Lithium Niobate) has worked at a low power and most likely can be scaled to high power. In general, the various matters we must consider include:

- Nonlinear-optical coefficient: Does the crystal produce a strong sum-frequency optical polarization, at the intensities furnished by the lasers?

- Phase matching: Can the coherence length be made sufficient to convert the input beams to the desired output?

- High-power operation: Will the temperature rise affect the phase matching?

- Nonlinear (two-photon) absorption: Can high efficiency be maintained in the presence of several powerful beams, the sum of whose energies exceeds the material's band gap?

- Damage: Will the material suffer damage by being exposed to the various high-power beams?

To the extent of our experiments, PPLN meets all of these criteria even when used in a singlepass geometry (i.e. no resonant cavity). 


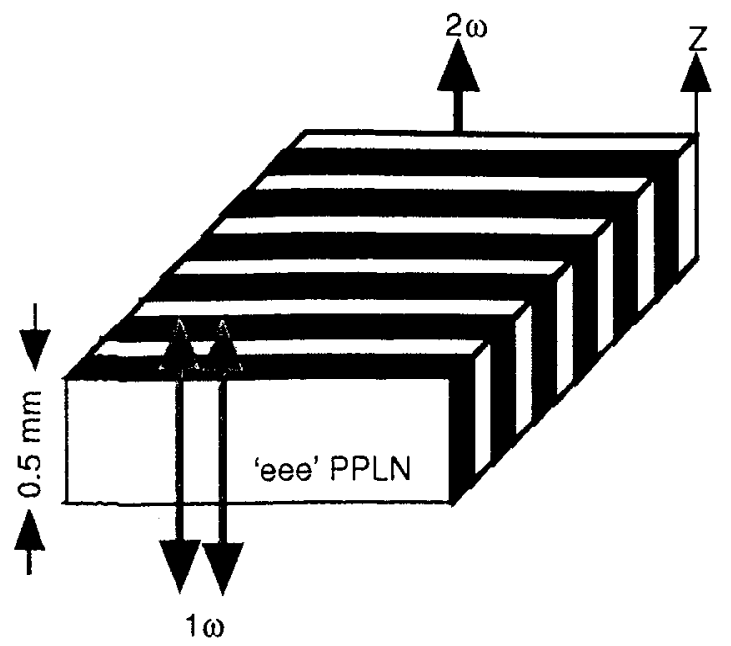

Figure 17: Input polarization and output polarization directions for 'eee' PPLN. The shaded regions on the crystal represent the photolithographically controlled, ferroelectric domain inversions. By changing the periodicity, the wavelengths for which sum frequency generation efficiently occurs can be controlled. A 9.0 micron period is optimum for SFG of 1064 and $1319 \mathrm{~nm}$.

Most crystals have refractive-index dispersion that causes the low- and high- frequency waves to get out of phase. When a crystal is birefringent, use of different polarizations for at least one of the waves can allow preservation of the phase matching. Unfortunately, this normally reduces the nonlinear-optical response (which is typically strongest when all the electric fields have the same polarization.) It is also possible, by microscopically reversing the material's domain orientations, to "flop" the preferred axis just at the exact distance at which the waves would have been exactly out of phase. Thus parallel-polarized waves can stay phase-matched all the way through a long crystal, greatly improving the nonlinear-optical performance. This "periodic poling" is done with electrodes whose period is adjusted to compensate the material refractiveindex dispersion between the wavelengths of interest. For matching visible and IR beams, this period is generally near 10 microns. A schematic of a periodically-poled crystal appears in Fig. 17 , for which all three beams have extraordinary polarization (hence the designation "eee"). Periodically-poled lithium niobate and lithium tantalate (PPLN and PPLT respectively) have 'come of age' and are now routinely available for near-infrared generation (with $15-30 \mu \mathrm{m}$ period gratings.) Shorter-period gratings appropriate for visible-light generation are more difficult to produce reliably owing to domain-wall interactions during poling. Within the last few years, however, the production of short-period gratings (i.e. $6.8 \mu \mathrm{m}$ ) for second-harmonicgeneration of $1064 \mathrm{~nm}$ has developed to the point of commercial viability. PPLN (and potentially PPLT) may now be considered as a potential replacement for either KTP or LBO for intracavity and/or external harmonic generation. The introduction of periodically-poled crystals has in fact revolutionized the prospects for frequency-conversion of continuous-wave lasers, a break-through that is particularly relevant to the $\mathrm{CW}$ approach for guide star lasers. Periodic poling allows use of greatly-enhanced (6-10 times larger) nonlinear coefficients not available with birefringent phase matching, leading to single-pass SHG efficiency increases of factors of 36-100. This removes the need for cavity-enhancement of the IR fields, and a simple, robust single-pass sum-frequency operation becomes adequate, providing a huge advantage in system simplicity. 


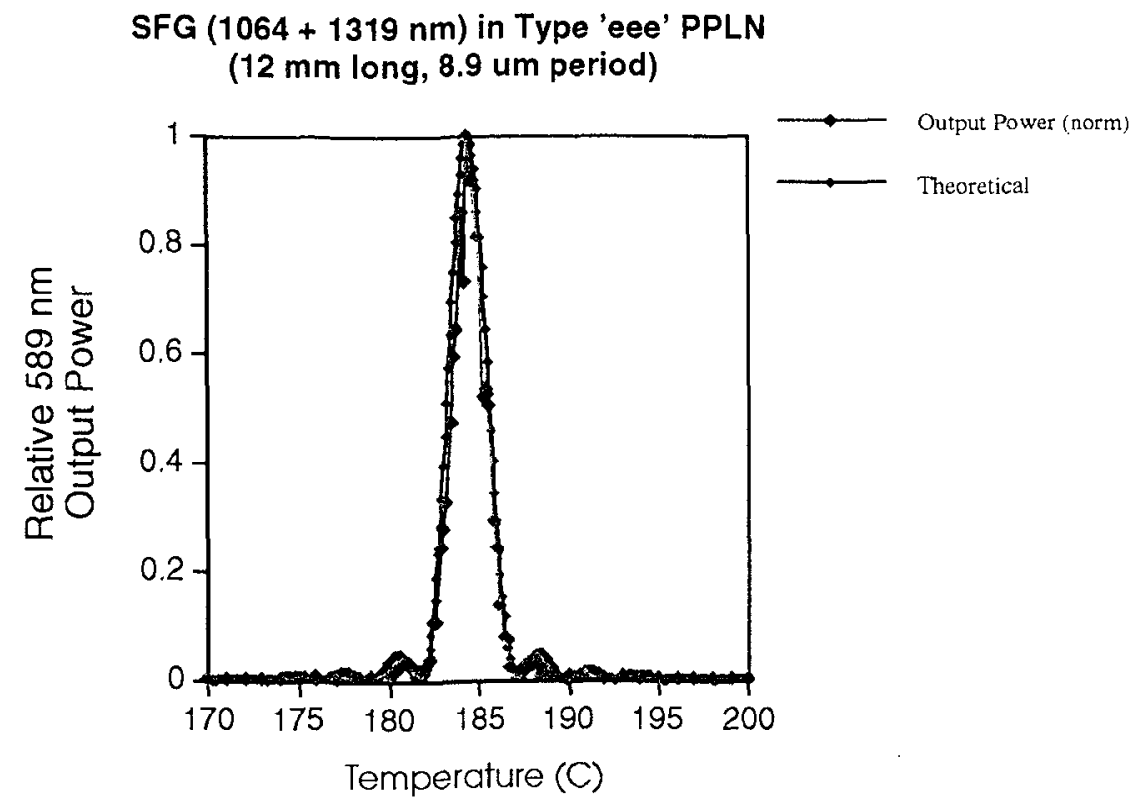

Figure 18: Theoretical and experimental temperature tuning curves of commerciallyavailable PPLN. The good agreement indicates that the poling period was extremely uniform.

When we constructed a powerful (over 2 Watt) Yb:silica fiber amplifier, we raised the drive to the PPLN crystal. We also obtained a longer piece: $5 \mathrm{~cm}$. Using the $5 \mathrm{~cm}$ PPLN crystal, with 2.3 $\mathrm{W}$ at $1064 \mathrm{~nm}$ and $0.35 \mathrm{~W}$ at $1319 \mathrm{~nm}$, we generated $90 \mathrm{~mW}$ of $589 \mathrm{~nm}$ light (outside the crystal, after suffering some loss) by simply focusing the light into the crystal. From these moderatepower experiments, we have developed a scaling relationship with which sum-frequencygeneration efficiencies in PPLN can be calculated. See Eq. 1 below, where $\mathrm{P}_{589}$ is the generated output power (W), $\mathrm{P}_{1064}$ and $\mathrm{P}_{1319}$ are the respective input powers (W), and $\mathrm{L}$ is the PPLN crystal length $(\mathrm{cm})$.

The relationship between output visible power P589 and input IR powers at 1064 and $1319 \mathrm{~nm}$ is

$$
\mathrm{P}_{589}=\left(0.030 \mathrm{~W}^{-1} \mathrm{~cm}^{-1}\right) * \mathrm{~L}^{*} \mathrm{P}_{1064} \mathrm{P}_{1319}
$$

where the powers are in Watts and the crystal length $\mathrm{L}$ is in $\mathrm{cm}$. We have determined that, with co focal focusing of the laser beams into a $5 \mathrm{~cm}$ "off-the-shelf" PPLN crystal, $\left(0.030 \mathrm{~W}^{-1} \mathrm{~cm}^{-1}\right)$ * $\mathrm{L} \sim 0.15 /$ Watt. We call the scaling parameter $\left(0.030 \mathrm{~W}^{-1} \mathrm{~cm}^{-1}\right)$ the "figure of merit," a simple number that allows us to assess the IR power requirements. If we did nothing but raise the IR powers (and for the sake of argument, made them equal), we would conclude that two $\sim 8$ Watt IR lasers could be mixed to generate $\sim 9$ Watt orange light. We are not sure that the mixing crystal will withstand this power density. So, we propose to "sneak up on" the high power level by generating a lower power at first. Also, the power density in the crystal can be 
straightforwardly reduced by working with elliptical beams (i.e. still Gaussian beams but with an aspect ratio different from unity) by expanding them in one dimension. Our projection for the single-head "subscale" $1319 \mathrm{~nm}$ amplifier mentioned above is that at least 1.0 Watt orange light will be produced. We will be able to demonstrate the ability to transform the optical beams back and forth between round and elliptical. There is a good chance that PPLN samples we obtain in the future will have higher figures of merit than the ones we used in the preliminary experiments.

The importance of the development of PPLN for this application can not be understated. The parameters relevant for doubling utilizing KTP, LBO, bulk $\mathrm{LiNbO}_{3}$ and PPLN are shown in Table III. In order to use Eq. 1 for other materials, the "figure of merit" $\left(0.030 \mathrm{~W}^{-1} \mathrm{~cm}^{-1}\right)$ needs to be reduced to account for the smaller nonlinearity $\left(\mathrm{deff}^{2}\right)$ of the alternative crystals. As the crystal is changed from $\mathrm{LBO}, \mathrm{KTP}$, or bulk $\mathrm{LiNbO}_{3}$, the scaling constant becomes 0.00006 , $0.001,0.0025$ respectively. The recent work of Moosmüller and Vance ${ }^{14}$ utilizing a $5 \mathrm{~cm}$ long bulk lithium niobate reflects this change in efficiency. Utilizing $0.70 \mathrm{~W}$ and $0.35 \mathrm{~W}$ sources at 1064 and $1319 \mathrm{~nm}$, respectively, they generated $3.2 \mathrm{~mW}$. Through the simple substitution of PPLN in the experiment, the generated output power would increase an order of magnitude to 33 $\mathrm{mW}$.

Table III. Comparison of LBO, PPLN, and KTP for Sum Frequency Mixing of 1.319 and $1.064 \mu \mathrm{m}$ Light

\begin{tabular}{|c|c|c|c|c|}
\hline $\begin{array}{c}\text { Material / } \\
\text { Process }\end{array}$ & $\begin{array}{c}\text { Phase matching } \\
\text { Angle/Period } \\
(\theta, \varphi)\end{array}$ & $\begin{array}{c}\text { Angular } \\
\text { Sensitivity } \\
\beta_{\theta} \\
(\mathrm{cm}-\mathrm{rad})^{-1}\end{array}$ & $\begin{array}{c}\text { deff } \\
(\mathrm{pm} / \mathrm{V})\end{array}$ & $\begin{array}{c}\text { Nonlinearit } \\
\mathrm{y} \\
\mathrm{C}^{2} \\
\left(\mathrm{GW}^{-1}\right)\end{array}$ \\
\hline $\begin{array}{c}\text { KTP } \\
\text { Type II }\end{array}$ & $(80,90)$ & $1.6 \times 10^{3}$ & 3.2 & 55 \\
\hline $\begin{array}{c}\text { LBO Type II } \\
\text { T=23 }{ }^{\circ} \mathrm{C}\end{array}$ & $(90,29)$ & $5.71 \times 10^{2}$ & 0.84 & 4 \\
\hline $\begin{array}{c}\text { LiNbO3 } \\
\text { Type I } \\
\text { T=70 }{ }^{\circ} \mathrm{C}\end{array}$ & $\begin{array}{c}(90,0) \\
\text { NCPM }\end{array}$ & 0 & & \\
\hline $\begin{array}{c}\text { PPLN } \\
(\text { eee })\end{array}$ & $\begin{array}{c}\text { NCPM } \\
9.01 \text { microns }\end{array}$ & 0 & 5.19 & 66 \\
\hline
\end{tabular}

NCPM = noncritically phase matched; lower $\beta_{\theta}$ is advantageous, due to reduced alignment sensitivity and option to focus tighter. Higher values of $\mathrm{C}^{2}$ imply better conversion efficiency.

The "thermally limited power", $\mathrm{P}_{\mathrm{av}}$, figure of merit $^{23}$ allows the comparison of the characteristic average power that can be tolerated by a given frequency conversion process, while maintaining a high conversion efficiency.

A desirable material has a large "average power figure of merit" which comes from a small optical absorption coefficient $\alpha$, a small thermal sensitivity $\beta_{\mathrm{T}}$, a large thermal conductivity $\kappa$, and a large optical nonlinearity $C^{2}$. In Table IV, the thermal average power efficiency limit $P_{t h}$ is calculated for sum frequency generation of 1064 and $1319 \mathrm{~nm}$. KTP, LBO, and PPLN have 
comparatively high potential for average power second harmonic generation. However, due to the higher nonlinear coupling, PPLN is optimum for CW frequency conversion.

Table IV. Average power figure of merit for sum-frequency mixing of 1064 and $1319 \mathrm{~nm}$.

\begin{tabular}{|c|c|c|c|c|c|}
\hline $\begin{array}{c}\text { Material } \\
\text { Process }\end{array}$ & $\begin{array}{c}\text { Thermal } \\
\text { acceptance } \\
\Delta \mathrm{T}-\mathrm{L} \\
\left(\mathrm{cm}-{ }^{\circ} \mathrm{C}\right)\end{array}$ & $\begin{array}{c}\text { Thermal } \\
\text { Sensitivity } \\
\beta_{\mathrm{T}} \\
\left.\left(\mathrm{cm}-{ }^{-} \mathrm{C}\right)\right)^{-1}\end{array}$ & $\begin{array}{c}\text { Thermal } \\
\text { Conductivity } \\
\kappa \\
\left(\mathrm{W} /\left(\mathrm{cm}-{ }^{\circ} \mathrm{C}\right)\right)\end{array}$ & $\begin{array}{c}\text { Optical } \\
\text { Absorption }\end{array}$ & $\begin{array}{c}\text { Threshold } \\
\text { Average } \\
\text { Power } \\
\mathrm{P}_{\text {th }} \\
(\mathrm{kW})\end{array}$ \\
\hline $\begin{array}{c}\text { KTP } 2 \omega \\
\text { Type II }\end{array}$ & $\sim 25$ & $\sim 0.22$ & 0.033 & $1-5 \% / \mathrm{cm}$ & 0.36 \\
\hline $\begin{array}{c}\text { LBO } \\
2 \omega I I \\
\mathrm{~T}=23{ }^{\circ} \mathrm{C}\end{array}$ & 8.1 & 0.69 & 0.035 & $>0.25 \% / \mathrm{cm}$ & 0.63 \\
\hline $\begin{array}{c}\text { LiNbO3 } \\
2 \omega I \\
\mathrm{~T}=100 \\
{ }^{\circ} \mathrm{C}\end{array}$ & 1.25 & 4.45 & 0.033 & $2 \% / \mathrm{cm}$ & 0.14 \\
\hline $\begin{array}{c}\text { PPLN } \\
(\mathrm{eee})\end{array}$ & 2.89 & 1.85 & 0.033 & $2 \% / \mathrm{cm}$ & 0.7 \\
\hline
\end{tabular}

We can determine the average power limit of the phase matching process for sum frequency generation by determining the temperature gradients expected in the crystal. The center to edge temperature rise is given by

$$
\Delta \mathrm{T} \text { ce } \quad=\frac{\alpha P \text { av }}{\mathrm{M} 8 \kappa}
$$

$M$ is the ratio of the beam height to its width (beam taken as $M=5$ ), $\alpha$ is the absorption coefficient, $\mathrm{P}_{\mathrm{a}}$ is the input average power, and $\kappa$ is the thermal conductivity. Utilizing these values, we estimate the transverse and longitudinal rise in, given a $20 \mathrm{~W} 1064 \mathrm{~nm}$ source, a $20 \mathrm{~W}$ $1319 \mathrm{~nm}$ source, generating $12 \mathrm{~W}$ of $589 \mathrm{~nm}$ light. The absorption coefficient for both 1319 as well as $1064 \mathrm{~nm}$ is $0.25 \% / \mathrm{cm}$. The optical absorption at $589 \mathrm{~nm}$ is much larger, $2 \% / \mathrm{cm}$. Utilizing these values, the calculated transverse rise in temperature is $\Delta \mathrm{T}_{\mathrm{ce}}=0.26^{\circ} \mathrm{C}$, within the thermal tolerance of PPLN of $0.58^{\circ} \mathrm{C}$.

Photorefraction remains as one important issue concerning the use of PPLN for this application. Photorefraction in lithium niobate is believed to be caused by a light-induced charge transport mechanism. The induced space charge modulates the refractive index through the electro-optic effect, resulting in 'beam spreading'. ${ }^{24}$ Several factors may mitigate the effects of photorefraction in PPLN vs. bulk lithium niobate. In principle, a grating with a $50 \%$ duty cycle (equal portions of $+\mathrm{Z}$ and $-\mathrm{Z}$ domains) should show a cancellation of the photorefractive effect, due to the alternating polarity of neighboring domains that pull the space charges in opposite directions. ${ }^{26}$ Operating at elevated temperature $\left(>100^{\circ} \mathrm{C}\right)$ also significantly reduces the 
photorefractive effect by increasing the crystal's conductivity, draining off the space charge. However, photorefractive effects are still observed in PPLN, even operating at elevated. temperature.

Recent results illustrate the magnitude of the $532 \mathrm{~nm}$ SHG (second harmonic generation) power density required before the photorefractive effect is unmanageable: $7 \mathrm{~W}$ of SHG in a 45 micron spot size was found to be one limit of operation. ${ }^{26}$ This leads to a SHG power irradiance of 100 $\mathrm{kW} / \mathrm{cm}^{2}$. Another, more conservative value, is derived from the threshold at which a photorefractive effect was observed in PPLN: $10 \mathrm{~mW}$ in a 40 micron spot diameter or a power irradiance of $0.8 \mathrm{~kW} / \mathrm{cm}^{2}{ }^{24}$ The wide spread (over a factor of 100 ) in these two intensities makes it difficult to establish a true operating-intensity limit.

Some wavelength dependence is expected for the tolerable operating powers. Photorefraction in PPLN used for $1064 \mathrm{~nm}$ SHG is presumably due to the simultaneous presence of both 1064 and $532 \mathrm{~nm}$ light. Nonlinear absorption of both a 1064 and $532 \mathrm{~nm}$ photon leads to a total energy near the hand gap of I ithium Niobate. Photorefraction is not observed during SHG of $1319 \mathrm{~nm}$ light however, since the nonlinear process involving a $1319 \mathrm{~nm}$ and a $660 \mathrm{~nm}$ photon lies well below the band gap. From this observation, we can interpolate that photorefractive effects for SFG between $1319 \mathrm{~nm}$ and $1064 \mathrm{~nm}$ will be less severe than that of $532 \mathrm{~nm}$ generation.

Using the result of Batchko, ${ }^{25}$ we can design around the photorefractive limit of commercially available PPLN - and expect results which will be more robust. Recognizing the importance of photorefraction as a limit to scaling of PPLN well beyond Batchko's measured limit of $2.7 \mathrm{~W}$ level, LLNL recently awarded Stanford University a contract to develop periodically poled crystals with higher resistance to photorefraction. $\Lambda$ s a result of these efforts, several techniques have been developed and are in the process of commercialization. The first is the recognition that PPLT (periodically poled lithium tantalate) has a higher intrinsic resistance to photorefraction, simply due to a larger band-gap relative to PPLN. (Lithium tantalate is isostructural to lithium niobate.) In addition, the most recent result has been the elimination of photorefraction in stoichiometric lithium niobate (in which the composition is accurately controlled. $)^{27}$ Thus, even though photorefraction is a risk issue, we think the world-wide interest in this problem within the laser community, together with the substantial progress already achieved, indicates that the risk is quite manageable. In any case, simple re-shaping of the beams into an ellipse $(M=5)$ provides an immediate solution to the problem based on using existing material. Again, because of the longer wavelengths we are employing compared to Batchko $^{25}$, we probably have an additional safety factor built into our system design.

\section{Commercialization Plan}

If successful, we intend to team with a commercial partner who could credibly supply the entire system to various users in the astronomy field. One natural choice, although not the only one we would consider, is Lightwave Electronics because they already supply the NPRO oscillators at $1064 \mathrm{~nm}$ and $1319 \mathrm{~nm}$ that are used in our proposed approach and because of their previous experience with PPLN-based systems. These NPRO systems have become the standard in both scientific and OEM applications where narrow band $1064 \mathrm{~nm}$ light is required in a robust, turnkey system that require both high reliability and ease of use. Additionally, the $1319 \mathrm{~nm}$ MOPA approach we have adopted here for its simplicity and robustness, is the same approach presently 
used by Lightwave in their $10 \mathrm{~W} 1064 \mathrm{~nm}$ LIGO system (Lightwave Model 6000), which is also the $1064 \mathrm{~nm}$ subsystem we are proposing to use here.

PPLN crystals are commercially available from several sources including Lightwave Electronics (Palo Alto, CA), Crystal Technology (Palo Alto, CA), NRO (National Research Optique in Quebec, Canada), and Deltronics (New Jersey). In order to make the best use of the most recent innovations in PPLN and PPLT, we will collaborate with one of the commercial sources.

Several vendors have already expressed an interest in this effort, for reasons beyond the scope of this proposal.

\section{Schedule and Budget Request}

We have proposed two R\&D paths below. The first path assumes the necessary funding is available from a combination of sources. The second is in line with the funding levels currently available from the Gemini Project.

Path1:

Our tentative schedule for completing the 1-W subscale $589 \mathrm{~nm}$ system is shown below. The time required from project funding until we fully demonstrate and characterize a 1-W subscale $589 \mathrm{~nm}$ system is estimated to be 10 months. We would require a total of $\$ 545 \mathrm{~K}$ to complete this

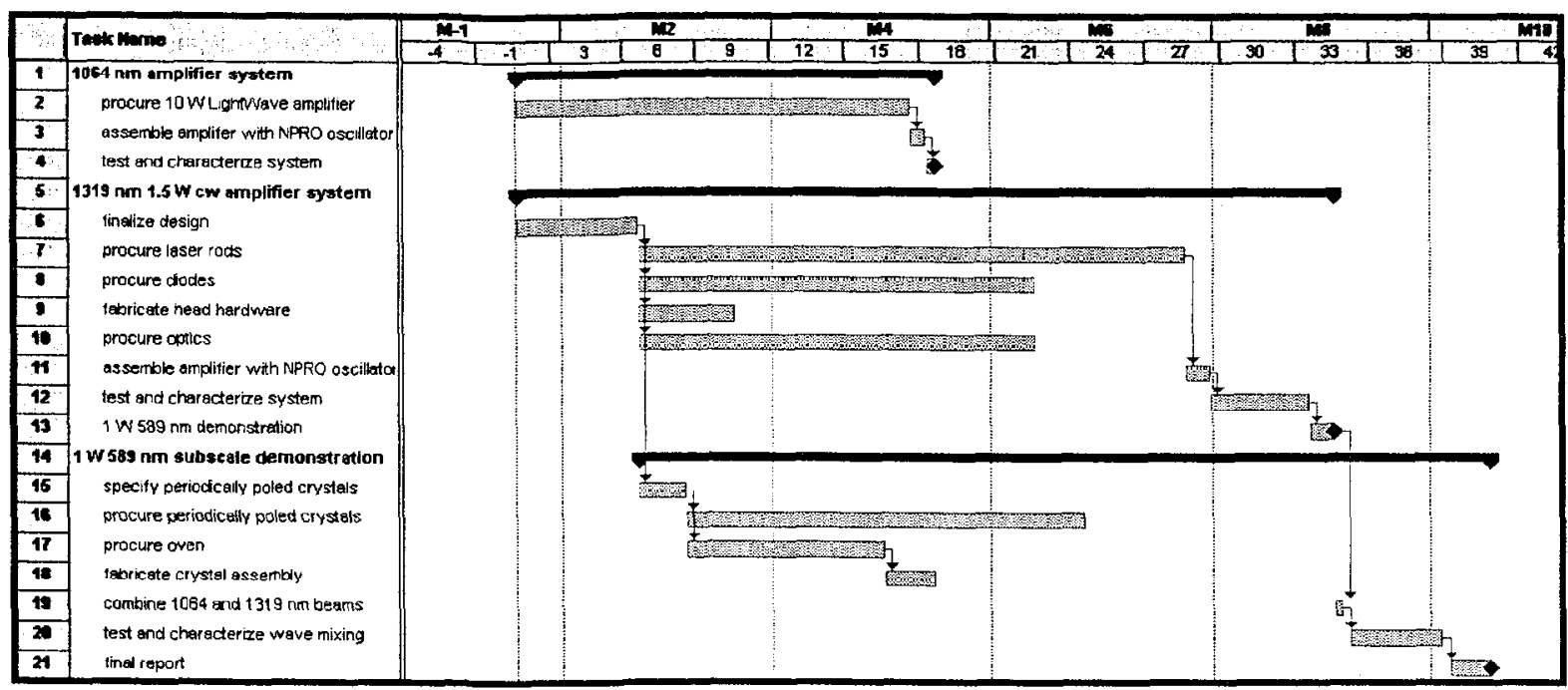

work. This campaign would address all risk issues, including the $1319 \mathrm{~nm}$ amplifier and high average power frequency-conversion with PPLN.

Table VI give a breakdown of this budget request and indicates the approximately $\$ 83 \mathrm{~K}$ in equipment that will be provided by LLNL on a loan basis to complete this work. The hardware fabricated in our proposal will be directly applicable to a full scale, $10 \mathrm{~W} 589 \mathrm{~nm}$ system. The full $10 \mathrm{~W} 589 \mathrm{~nm}$ system will require the addition of another rod assembly to the $1319 \mathrm{~nm}$ amplifier to bring the average $1319 \mathrm{~nm}$ power to $>10 \mathrm{~W}$, and another amplification stage to the $1064 \mathrm{~nm}$ system to bring the average $1064 \mathrm{~nm}$ average power to $\sim 20 \mathrm{~W}$ (not covered in this proposal). Except for line broadening the $589 \mathrm{~nm}$ output, which could be accomplished using a simple and inexpensive phase modulator between the $1319 \mathrm{~nm}$ oscillator and amplifier, this proposed subscale system will demonstrate all the requirements of the Gemini guide star system in a robust, turn-key package. 
Table VI Budget request for subscale 1-W $589 \mathrm{~nm}$ system

Resolves risk issues associated with high average power frequency-conversion based on PPLN, and demonstrates $1319 \mathrm{~nm}$ amplifier

\begin{tabular}{|l|l|}
\hline Optics & $\$ 30 \mathrm{~K}$ \\
\hline $\begin{array}{l}\text { Laser rods for } 1319 \mathrm{~nm} \\
\text { amplifier }\end{array}$ & $\$ 20 \mathrm{~K}$ \\
\hline $1319 \mathrm{~nm}$ hardware & $\$ 30 \mathrm{~K}$ \\
\hline Diodes & $\$ 25 \mathrm{~K}$ \\
\hline Diode Power supply & $\begin{array}{l}(\$ 7 \mathrm{~K}) \text { supplied by LLNL } \\
\text { loan }\end{array}$ \\
\hline Diode chillers & $\begin{array}{l}(\$ 10 \mathrm{~K}) \text { supplied by LLNL } \\
\text { loan }\end{array}$ \\
\hline Nonlinear crystal & $\$ 30 \mathrm{~K}$ \\
\hline Crystal oven & $\$ 10 \mathrm{~K}$ \\
\hline $\begin{array}{l}\text { Lightwave (LIGO) close- } \\
\text { coupled amplifier for } 1064 \\
\text { nm NPRO }\end{array}$ & $\$ 100 \mathrm{~K}$ \\
\hline 1064 nm Lightwave NPRO & $\begin{array}{l}\text { (\$33K) supplied by LLNL } \\
\text { loan }\end{array}$ \\
\hline 1319 nm Lightwave NPRO & $\begin{array}{l}\text { \$33K) supplied by LLNL } \\
\text { loan }\end{array}$ \\
\hline Scientist & 6 months $\$ 120 \mathrm{~K}$ \\
\hline Technician & 12 months $\$ 180 \mathrm{~K}$ \\
\hline & Total $\$ 545 \mathrm{~K}$ \\
\hline
\end{tabular}

Path 2:

As an alternative to the $\$ 545 \mathrm{~K}$ program outlined above, we have also costed out a more modest program that addresses the development issues associated with demonstrating high average power frequency-mixing using a periodically poled mixing crystal. It does not, however, completely address the development issues associated with developing a $1319 \mathrm{~nm}$ amplifier system. In this scenario, we propose to demonstrate $1 \mathrm{~W}$ of second harmonic generation at 532 $\mathrm{nm}$, by frequency doubling a $10 \mathrm{~W} 1064 \mathrm{~nm} \mathrm{CW}$ laser system. Using a commercially procured $10 \mathrm{~W} \mathrm{CW} 1064 \mathrm{~nm}$ laser system (the same Lightwave system we propose to use for the 1-W subscale $589 \mathrm{~nm}$ demonstration) we would simply frequency double the output of the laser. In this case, LLNL would still supply the needed $1064 \mathrm{~nm}$ NPRO laser oscillator on a loan basis. The $1064 \mathrm{~nm}$ amplifier would be directly applicable in future programs to a system designed to generate $589 \mathrm{~nm}$ using our outlined approach, but the frequency mixing crystal would not, as it would not have the correct poling period for $589 \mathrm{~nm}$ generation. Table VII gives a budget breakdown for this particular program for which we are requesting $\$ 300 \mathrm{~K}$, and which would require approximately 7 months to complete. We would nevertheless be able to ascertain the relative value of the $1064 \mathrm{~nm}$ and $1319 \mathrm{~nm}$ cross sections, which would provide enhanced confidence that the $1319 \mathrm{~nm}$ amplifier would operate as predicted. 
Table VII Budget request for 1-W 532 nm system

Resolves risk issues associated with high average power frequency-conversion based on PPLN, and suggests scaling of $1319 \mathrm{~nm}$ amplifier performance

\begin{tabular}{|l|l|}
\hline Optics & $\$ 10 \mathrm{~K}$ \\
\hline Nonlinear crystal & $\$ 30 \mathrm{~K}$ \\
\hline Crystal oven & $\$ 10 \mathrm{~K}$ \\
\hline $\begin{array}{l}\text { Lightwave (LIGO) close- } \\
\text { coupled amplifier for } 1064 \\
\text { nm NPRO }\end{array}$ & $\$ 100 \mathrm{~K}$ \\
\hline 1064 nm Lightwave NPRO & $\begin{array}{l}\text { \$33K) supplied by LLNL } \\
\text { loan }\end{array}$ \\
\hline Scientist & 3 months $\$ 60 \mathrm{~K}$ \\
\hline Technician & 6 months $\$ 90 \mathrm{~K}$ \\
\hline
\end{tabular}

Total $\$ 300 \mathrm{~K}$

We have proposed a credible route to a reliable guide star system. It is based on our own handson laboratory experience in constructing a $589 \mathrm{~nm}$ system that, except for low power, meets most of the technical requirements. The $\mathrm{kW}$-level laser we developed in support of Boeing-sponsored work, together with our Watt-level PPLN $589 \mathrm{~nm}$ frequency-conversion results, suggest that the risk is manageable. We have provided considerable engineering detail regarding our approach to risk reduction and scaling to high average power. Lastly, we have identified potential commercial partners who can help make this technology accessible to a wide variety of astronomers. 


\section{SECTION IV}

\section{Related funding}

The respondents have internal and CFAO funding at the $\$ 150 \mathrm{~K}$ level to do a study of the laser technologies currently available or proposed, and to identify a specific design for further investigation. This project will be complete with the generation a written report to LLNL management and the CFAO. It is our intention to use a portion of this existing funding to build a $1319 \mathrm{~nm}$ oscillator to evaluate the uncertainty in YAG cross-sections in the literature. This will allow the completion of the cavity design for the Y-branch oscillator and the $1319 \mathrm{~nm}$ amplifier scaling. With this information, an informed down selection can be made. Pending the success of the CFAO report and this response to AURA, additional funding may become available from the CFAO, CELT, or NSF ATI funds. We have submitted a proposal for internal LLNL funding, however, assuming a grant is awarded, funds will not be available until November, 2000 .

\section{References}

1. K. Avicola, J. M. Brase, J. R. Morris, H. D. Bissinger, J. M. Duff, H. W. Friedman, D. T. Gavel, C. E. Max, S. S. Olivier, R. W. Presta, D. A. Rapp, J. T. Salmon, and K. E. Waltjen, J. Opt. Soc. Am. A 11, 825 (1994).

2. C. E. Max, S. S. Olivier, H. W. Friedman, J. An, K. Avicola, B. V. Beeman, H. D. Bissinger, J. M. Brase, G. V. Erbert, D. T. Gavel, K. Kanz, M. C. Liu, B. Macintosh, K. P. Neeb, J. Patience, K. E. Waltjen, Science 277,1649 (1997)

3. H. W. Freidman, J. B. Cooke, P. M. Danforth, G. V. Erbert, M. Feldman, D. T. Gavel, S. L. Jenkins, H. E. Jones, V. K. Kanz, T. C. Kuklo, M. J. Newman, E. L. Pierce, R. W. Presta, J. T. Salmon, G. R. Thompson, N. J. Wong, SPIE Conference on Adaptive Optical System Technologies, Kona, HI, 3353, 260 (1998).

4. T. Jeys, A. A. Brailove, A. Mooradian, Appl. Opt. 28, 2588 (1989).

5. T. Jeys, The Lincoln Laboratory Journal 4, 133 (1991).

6. E. J. Kibblewhite, F. Shi, Proc. SPIE Conference on Adaptive Optical System Technologies, Kona, HI, 3353, 300 (1998).

7. M. B. Danailov and P. Apai, J. Appl. Phys. 75, 8240 (1994).

8. P. A. Schulz and T. H. Jeys, Opt. Lett. 18, 1630 (1993).

9. W. L. Nighan, B. Craig, Laser Focus World, pg. 63, April, 1996.

10. "43 Watt CW Ti:Sapphire Laser" G. V. Erbert, I. L. Bass, R. P. Hackel, S. Jenkins, K. Kanz, J. A. Paisner, Conference on Lasers and Electro-Optics, Baltimore, Maryland, May 1991.

11. "High Power Continuous-wave Ti:Sapphire Laser", G. V. Erbert, I. L. Bass, R. P. Hackel, Sherman L. Jenkins, V. K, Kanz, J. A. Paisner, United States Patent 5,247,527, September 21, 1993.

12. M. Oka and S. Kubota, Opt. Lett. 13, 805 (1988).

13. G. Erbert, K. Kanz, private communication.

14. H. Moosmüller and J. D. Vance, Opt. Lett. 22, 1135 (1997).

15. A. E. Siegman, Lasers (University Science Books, Mill Valley CA, 1986) pg. 537.

16. R. J. Beach, E. C. Honea, S. B. Sutton, C. M. Bibeau, J. A. Skidmore, M. A. Emanuel, S. A. Payne, P. V. Avizonis, R. S. Monroe and D. G. Harris, "High-Average-Power Diode-Pumped Yb:YAG Lascrs," to be published in Proc. SPIE, "Advanced High Power Lasers," Osaka, Japan, Nov 1999. 
17. R.J. Beach, Appl. Opt. 35, 2005 (1996).

18. U. Deserno, D. Ross, and G. Zeidler, Phys. Lett. 28A ,422, (1968)

19. T.R. Loree, L.M. Sherman, and J.M. Thorne, IEEE J. Quant. Elec., p 371, July 1975.

20. S. Kuch, L. Fornasiero, E. Mix, and G. Huber, Appl. Phys. B 67, 151 (1998).

21. R. Beach, W. J. Bennett, B. L. Freitas, D. Mundinger, B. J. Comaskey, R. W. Solarz and M. A. Emanuel, IEEE J. Quant. Elect. 28, 966 (1992).

22. R. Beach, M.A. Emanuel, B. L. Freitas, J. A. Skidmore, N.W. Carlson, W. J. Bennett, and R. W. Solarz, SPIE Vol. 2383, pp. 283-297, 1995.

23. S. P. Velsko, SPIE Laser Host and Nonlinear Crystals II (Jan. 18, 1993).

24. B. Sturman, M. Aguilar, F. Agullo-Lopez, Appl. Phys. Lett. 69, pp. 1349-1351.

25. G. D. Miller et. Al. , CNOM Annual Report, pp. 15-19 (1997).

26. S. Tidwell, J. Seamans, P. Roper, 'Moderate Power CW Pumped PPLN' Post deadline paper CPD25, (CLEO '97 Baltimore Md).

27. Fejer et. al., Advanced Solid State Lasers Conference, February, 2000.

\section{Qualifications}

The LLNL Laser Program has a substantial infrastructure for the design and prototyping of advanced solid-state laser systems. In particular, the Laser Science and Technology Program has a history of successful work-for others contracts. The program is comprised of a group of diverse individuals who can address all aspects of a turn-key laser system delivery. This includes a core group of scientists and engineers, with a dedicated electrical, mechanical, optical and software support staff for system design, integration and packaging. In addition to having demonstrated a $589 \mathrm{~nm}$ laser system, which has a direct and compelling connection to the present proposal, we have had extensive experience in devising a wide variety of high average power solid state laser systems. In many cases, we have a retained a world record for power for at least a period of time. Examples include a $110 \mathrm{~W} 2010 \mathrm{~nm}$ Tm:YAG laser, $140 \mathrm{~W}$ doubled $532 \mathrm{~nm} \mathrm{Nd:YAG}$ laser, and our $1080 \mathrm{~W} 1030 \mathrm{~nm}$ Yb:YAG laser delivered to Boeing Corp. Technical matters with which we have had extensive experience include thermal management, diode pump arrays, parasitic suppression, and high power optics. As a result, we are confident that we will be able to resolve the average-power issues surrounding the guide star laser system. The program also has a large-scale diffractive optics facility providing components for customers throughout the world. It has successfully delivered several integrated materials processing laser systems to customers over the last few years. Finally, several successful large scale laser facilities, among them the $10 \mathrm{TW}, 100 \mathrm{TW}$, Petawatt, Falcon and Mercury Laser Facilities have been designed and constructed by members of this program. The LS\&T program is in an excellent position to address the challenges of developing the next generation of guide star lasers.

\section{Curriculum Vitae}

\section{Dr. Raymond Beach}

Raymond J. Beach has 17 years of experience in laser physics and related fields. He received his Ph.D. in experimental laser physics from Columbia University in New York City in 1983. After graduating from Columbia, he remained there until 1986 in various positions as a Post-Doctoral Researcher in the Physics Department, a Research Scientist in the Electrical engineering Department, and an Assistant Professor in the Physics Department. During this period he performed research in the fields of optical coherent transient physics and laser assisted processing of silicon. Since 1986, he has been a member of the Laser Program at Lawrence 
Livermore National Laboratory where he is presently a Group Leader for diode-pumped solid state lasers in the Laser Science and Technology Group. Since joining the LLNL Laser Program, his research has focused on the design and development of advanced solid-state lasers, the packaging of high average power laser diode arrays, and the radiance conditioning of laser diode arrays. Dr. Beach has been awarded two R\&D 100 awards for work he has performed in the area of laser diode packaging and diode-pumped solid-state lasers. He has published over 30 scientific papers and has 7 issued patents.

\section{Dr. Christopher Ebbers}

Christopher A. Ebbers has 13 years of experience in laser physics and nonlinear optics. In 1991 he received his Ph.D. in solid state physics from the University of California at Davis, Department of Applied Science. After graduating from Davis, he took two postdoctoral positions at Lawrence Livermore National Laboratory. During this period he performed research concerning defect formation in crystals and precision characterization of optical crystals. He is presently a staff scientist in the Laser Science and Technology Program. Since joining the LLNL Laser Program, his research has focused on the design and development of high average power nonlinear optical devices and advanced solid-state lasers. Dr. Ebbers has been awarded an R\&D 100 award and a LLNL Director's Award for work he has performed in the area of reliable, highaverage-power frequency conversion. He has published over 15 scientific papers and has 2 issued patents. He is also an adjunct faculty member at Las Positas College.

\section{Gaylen V. Erbert}

Gaylen V. Erbert has over 20 years experience in laser engineering and related fields. He received his BS degree in physics and mathematics from the University of New Mexico in 1979. After graduating, he took a position at CVI Laser Corporation as a thin film physicist, responsible for the design and production of high power laser optics. Since January of 1981 he has been a member of the Laser Program at Lawrence Livermore National Laboratory. During this period he was responsible for the development of several high average power laser systems including world class frequency doubled Nd:YAG lasers, high average power Ti:sapphire lasers and narrow ban tunable dye laser systems. He was a team member involved in the development of field able dye laser systems for laser guide star applications. He is currently a project leader in the Laser Science and Technology Group responsible for the development of short pulsed lasers for industrial applications. He received the Director's Performance Award for his work in frequency doubled Nd:YAG lasers. He has several publications in laser development and spectroscopy as well as 2 issued patents.

\section{Hoang T. Nguyen}

Hoang T. Nguyen has 9 years of experience in advanced laser system design and diffractive optics with emphasize towards femtosecond laser. He received his B.S. in Laser Electro Optical Engineer from Oregon Institute of Technology in 1992. After graduating, he accepted a position at LLNL as Senior Laser Electro Optical Technologist, where he was responsible for experimental setup, design of optical systems for imaging characterization and detection, coordinating efforts of technical supports, operations, maintenance, and upgrade the Laser Program's 10 TW Short Pulse Laser Facility. This project chartered to investigate applications of ultra short high intensity laser interaction physics and femtosecond pulse laser system devclopment. In addition, he assisted in the development of a Terawatt Cr:LiSAF Laser and 
development of a Terawatt Cr:LiSAF Laser. In 1996 he accepted a position as Laser Optical Engineer in the Laser Program Femtosecond Laser Material Processing Group. His work encompassed the design and development of the first high average power femtosecond laser at LLNL, the devclopment of a new femtosecond material processing facility, the design, development, and evaluation of material processing techniques. His present focus is the design and development of advanced high average power laser system. Hoang T. Nguyen has been awarded two R\&D 100 awards for work in Femtosecond Laser Material Processing, and Lithography for Flat-Panel Displays. He has also received a DOE Weapons Recognition of Excellence Award and a Director's Performance Award for demonstrating the feasibility of laser cutting technology in support of the W87 Life Extension Program. He has 3 issued patents and has published over 12 scientific papers.

\section{Dr. Ralph Page}

Ralph Page has had over 20 years' experience in atomic, molecular, and optical physics. He earned his $\mathrm{Ph} . \mathrm{D}$. degree in 1987 at U. C. Berkeley working in the area of high-resolution, nonlinear laser spectroscopy and supersonic molecular beams. His subsequent spectroscopic research has included measurements of Rydberg structure of iron-period elements, and optical diagnostics of RF sputtering plasmas. Precise measurements of uranium-atom spectra and energy levels have also been an area of concentration. Novel light-generation techniques and saturation spectroscopy (optical pumping) have been a key part of this work. Since joining LLNL, Dr. Page has been actively involved in three types of laser-system developments. First, in the AVLIS program, he participated in design, construction, testing, and deployment of a high-average-power (kW-class) ultra-high-resolution dye laser system. Working in the ICF program, he helped discover a new class of infrared laser materials: transition-metal-doped II-VI compounds. Most recently, he has been a principal investigator in the use of high-resolution, high-power fiber lasers for tunable visible-light generation. During the 1992-1993 period of laser guide star experiments at LLNL, Dr. Page was responsible for assuring that the AVLIS dye laser system was tuned to the optimum wavelength for guide star excitation, and created an atomic reference standard in conjunction with the Fizeau wavemeter that had previously been the primary wavelength reference. Dr. Page has numerous publications on spectroscopy and laser development, as well as a few patents.

\section{Dr. Stephen A. Payne}

Dr. Payne received his Ph.D. at Princeton University in 1983 in the field of two-photon spectroscopy of crystals. Following his post-doctoral tenure at the University of Pennsylvania where he studied photochemical reaction dynamics on a picosecond time-scale, he was hired at LLNL. Since then, he has invented many laser crystals, such as Cr:LiSAF, Yb:S-FAP, LG-770 \& APG-2 (laser glasses), and Cr:ZnSe. He holds ten patents and has published 80 refereed journal articles. He has served as the General Chair of the Advanced Solid State Lasers Conference, and has won 4 R\&D-100 Awards. Dr. Payne recently received the "Excellence in Fusion Engineering Award" based on his work on diode-pumped solid-state lasers for fusion. He is presently manager of the Advanced Lasers and Components area within the Laser Science and Technology Program, where 12 professionals report to him regarding a variety of technical areas relating to solid state lasers, including diode pump fabrication, crystal growth, thermal modeling, and optical design. 